SILVIA HONDA TAKADA

\title{
Efeitos da anóxia neonatal no encéfalo de ratos: estudo da distribuição de neurônios imunorreativos a Fos
}

Dissertação apresentada ao Programa de Pós-Graduação em Ciências Morfofuncionais do Instituto de Ciências Biomédicas da Universidade de São Paulo, para obtenção do Título de Mestre em Ciências.

Área de concentração: Ciências Morfofuncionais

Orientador: Profa. Dra. Maria Inês Nogueira

SÃo PAULO 


\section{RESUMO}

TAKADA, S.H. Efeitos da anóxia neonatal no encéfalo de ratos: estudo da distribuição de neurônios imunorreativos a Fos. 122 f. Dissertação (Mestrado em Ciências Morfofuncionais) Instituto de Ciências Biomédicas, Universidade de São Paulo, São Paulo, 2009.

A anóxia neonatal, considerada um problema clínico mundial, é uma das mais importantes causas de lesão encefálica em neonatos e pode apresentar conseqüências graves e duradouras, dentre elas retardo mental, paralisia cerebral, epilepsia, deficiências auditivas e visuais e déficits comportamentais. As conseqüências anatômicas da privação de oxigênio nos neurônios em desenvolvimento vão desde morte celular a problemas na diferenciação de dendritos e axônios e no estabelecimento de sinapses. Estas anormalidades anatômicas, aparentemente mínimas, parecem ser base das disfunções comportamentais e psicológicas descritas. Os objetivos deste estudo foram validar o modelo de anóxia neonatal apresentado e efetuar a análise de neurônios imunorreativos à proteína Fos (IR-Fos) no encéfalo de ratos neonatos submetidos ao insulto anóxico. Foram utilizados 24 ratos albinos (Ratus norwegicus, linhagem Wistar) machos, neonatos (aproximadamente 30 horas de vida), pesando 6 a $8 \mathrm{~g}$, divididos em dois grupos experimentais: Anóxia $(n=12)$ e Controle $(n=12)$. Dez neonatos (Anóxia, $\mathrm{n}=5$; Controle, $\mathrm{n}=5$ ) foram submetidos aos testes de saturação periférica de oxigênio e catorze (Anóxia, $n=7$; Controle, $n=7$ ) foram utilizados na análise imunoistoquímica para proteína Fos. Para a exposição dos animais à anóxia, foi utilizada câmara semi-hermética de policarbonato, com temperatura mantida entre 35 e $37^{\circ} \mathrm{C}$. A câmara foi saturada com nitrogênio gasoso 100\%, num fluxo de 3 litros/minuto, pressão de $101,7 \mathrm{kPa}$, durante 25 minutos. O grupo Anóxia apresentou decréscimo de $75 \%$ no valor da saturação periférica de oxigênio durante a exposição ao nitrogênio nas condições experimentais descritas, enquanto o grupo Controle não apresentou alterações nos valores de saturação periférica de oxigênio durante o tempo estudado $(97 \% \pm 0,5)$. A análise do número de células IR-Fos mostrou ativação de áreas encefálicas relacionadas ao controle da respiração (núcleos do trato solitário, área postrema e núcleo reticular lateral da medula), inclusive com especificidade para algumas populações neuronais, estruturas límbicas (córtex entorrinal, caudado-putame e hipocampo) e núcleos da rafe (dorsal, magno, pálido e obscuro). Lesões em estruturas límbicas seguintes ao insulto anóxico são provavelmente correlacionadas aos déficits comportamentais, como déficits de memória espacial e aprendizagem; ainda, a ativação de núcleos da rafe sugere possível participação do sistema serotoninérgico na modulação respiratória. Estes dados sugerem que o modelo experimental de anóxia neonatal utilizado é eficiente em produzir privação temporária de oxigênio nos ratos neonatos, levando a respostas fisiológicas e metabólicas condizentes com a anóxia. Espera-se, com estes resultados, facilitar a compreensão dos eventos relacionados a neurodegeneração e neurorregeneração após anóxia neonatal e, se possível, abrir caminho para novas abordagens e perspectivas terapêuticas.

Palavras-chave: Anóxia. Neonatologia. Imunohistoquímica. Ratos. 


\begin{abstract}
TAKADA, S.H. TAKADA, S.H. Effects of neonatal anoxia in rat brain: study of Fosimmunoreactive neurons distribution. 122 f. Master thesis (Morfofunctional Sciences) Instituto de Ciências Biomédicas, Universidade de São Paulo, São Paulo, 2009
\end{abstract}

Neonatal anoxia, considered a clinical world-wide problem, is one of the most important causes of encephalic injury in neonate, it presents serious and lasting consequences like mental retardation, cerebral palsy, epilepsy, hearing and visual deficiencies and behavioral deficits. The anatomical consequences of oxygen deprivation in developing neurons are cellular death, alterations in neurites growth and synaptic establishment. These apparently minimal anatomical abnormalities seems to be the base of the described neural dysfunctions. The aim of this study is to validate the experimental model of neonatal anoxia and evaluate by Fos imunoreactivity (Fos-IR) the effects of anoxic insult. Twenty-four male Wistar neonates (approximately 30 hours, weighting 6-8 g) were divided in two groups: Anoxia $(n=12)$ and Control $(n=12)$. Ten neonates (Anoxia, $n=5$; Control, $n=5)$ were used in oxygen peripheric saturation test, and fourteen (Anoxia, $n=7$; Control, $n=7$ ) were used in Fos imunocitochemistry analisis. Anoxia was performed in a polycarbonate chamber, with temperature maintained between 35 and $37{ }^{\circ} \mathrm{C}$. The chamber was saturated by gaseous nitrogen $100 \%$ in a flow of 3 liters / minute, pressure of $101,7 \mathrm{kPa}$, during 25 minutes. The anoxic group presented decrease of $75 \%$ in the value of the peripheric saturation of oxygen during exposure to the nitrogen in the experimental described conditions while control group did not present alterations in the values of the peripheric saturation of oxygen during the studied time $(97 \% \pm 0,5)$. Fos-IR neurons analisis showed important activation of respiratory regions (solitary nucleus tract, lateral reticular nucleus and postrema area), with neuronal groups specificity, limbic strutures (entorhinal cortex, caudate-putame and hippocampus) and raphe nuclei (dorsal nucleus, magnus, obscurus and pallidus) in anoxic group when compared to control group. Limbic structures lesions following anoxic insult are probably correlated to behavioral deficits, like spatial memory and learning deficits and activation of raphe nuclei suggests possible serotonergic system participation in respiratory modulation. These data suggest that the experimental model of neonatal anoxia presented is efficient in producing temporary deprivation of oxygen in neonates rats, leading to physiologic and metabolic responses that characterize anoxia. We hope facilitate the understanding of neonatal anoxia neurodegeneration and neuroregeneration and possibly contribute for new approaches and therapeutic perspectives.

Keywords: Anoxia. Neonatalogy. Immunohistochemistry. Rats. 


\section{INTRODUÇÃO E REVISÃO DE LITERATURA}

\subsection{Anóxia neonatal}

A hipóxia é o estado de baixo teor de oxigênio nos tecidos orgânicos que pode ocorrer por diversos fatores, como obstrução física do fluxo sangüíneo em qualquer nível da circulação corpórea ou deslocamento para áreas com concentrações baixas de oxigênio no ar. A anóxia, considerada um agravante da hipóxia, é a condição onde a concentração de oxigênio ambiente é praticamente zero. Entre outros fatores que promovem anóxia está a isquemia (redução ou cessação de fluxo sanguíneo por hipotensão sistêmica, parada cardíaca ou doença vascular oclusiva), que deprime os níveis de oxigênio no leito vascular (NYAKAS et al., 1996; VANNUCCI, 2000).

A privação de oxigênio pode decorrer da asfixia, estado em que as trocas gasosas placentárias ou pulmonares são interrompidas, causando progressiva hipoxemia, que pode evoluir até estar associada à acidose, que pode ser respiratória, metabólica ou fisiológica. A acidose respiratória é decorrente de troca gasosa pulmonar ou placentária deficitária, enquanto que a metabólica ocorre devido ao acúmulo de ácido lático na corrente sanguínea e tecidos, em conseqüência da glicólise anaeróbica. Tipicamente, a asfixia está associada com um misto de acidoses metabólica e respiratória (NYAKAS et al., 1996).

O processo do nascimento por si só está associado com uma leve asfixia fisiológica: todos os neonatos apresentam redução na pressão parcial de oxigênio $\left(\mathrm{pO}_{2}\right)$ e pH durante o parto, característicos da asfixia. Esta asfixia fisiológica do nascimento não causa danos aos tecidos, a menos que fatores aumentem a predisposição do neonato a lesões decorrentes da privação temporária de oxigênio (GLUCKMAN et al., 2001). Por esta razão, eventos relacionados ao nascimento que podem causar danos ao encéfalo em desenvolvimento, estrutura mais susceptível no neonato, são considerados potencialmente perigosos para o bebê (JOHNSTON et al., 2002). Mais freqüentemente, as complicações estão relacionadas a anóxia, hipóxia, isquemia ou a combinação entre elas (BOHR, 2004). Atualmente existe forte evidência de que a lesão encefálica ocorre comumente no período perinatal imediato (considerada por alguns autores como período neonatal), podendo ser potencialmente tratável (GUNN e BENNET, 2008).

A hipóxia/anóxia perinatal é uma das mais importantes causas de lesão encefálica nos neonatos e pode apresentar conseqüências graves e permanentes (MIKATI et al., 2005; CHEN et al., 2007), sendo considerada um problema clínico mundial (MAJEED et al., 2007). 
A hipóxia/anóxia perinatal é o mais sério problema em países menos desenvolvidos, onde cuidados e precauções não estão sempre disponíveis ou aplicados adequadamente (COSTELLO et al., 1994). Nestes países, as crianças portadoras de paralisia cerebral associada ou não a outras seqüelas decorrentes de hipóxia/anóxia perinatal, por exemplo, correspondem a quase $70 \%$ dos pacientes atendidos em centros de reabilitação pediátrica.

Estatísticas sugerem incidência de asfixia perinatal em 2-4/1000 crianças nascidas a termo, mas um nível de incidência bastante alto, aproximadamente $60 \%$, em neonatos prematuros com baixo peso, constituindo grande preocupação para a saúde pública (VANNUCCI, 1997; LAVIOLA et al., 2004).

Cerca de 20 a $50 \%$ dos bebês asfixiados que apresentam seqüelas falecem durante os primeiros meses de vida (VANNUCCI, 1997), entretanto, estudos mostraram que estas taxas estão desatualizadas (WILSON-COSTELLO et al., 2005). Com os avanços tecnológicos e novos conhecimentos e estratégias terapêuticas, neonatos prematuros têm maiores taxas de sobrevivência quando comparadas com períodos anteriores (SUGUIHARA et al., 2005).

Fatores como a maturidade do encéfalo no momento da deficiência de oxigênio, a duração da asfixia, a vulnerabilidade regional e celular específica, dentre outros (CIRULLI, 2003), têm grande influência no aparecimento de problemas neurológicos, como retardo mental, paralisia cerebral, epilepsia, deficiências auditivas e visuais (JOHNSTON, 2002), distúrbios comportamentais, como prejuízo no aprendizado e memória espacial (HEDNER e LUNDBORG, 1980; DELL'ANNA et al., 1995a; DELL'ANNA et al., 1997; WAINWRIGHT et al., 2004; CASOLINI et al., 2005; ROGALSKA et al., 2006), respostas anormais ao estresse, e transtorno do déficit de atenção com hiperatividade (TDAH) (VOLPE, 1992; DELL'ANNA et al., 1993; FARAONE e BIEDERMAN, 1998; VANNUCCI et al., 1999; CANNON et al., 2002; CAPUTA et al., 2005). Estes distúrbios tendem a ser permanentes, persistindo por toda a vida (NYAKAS et al., 1996). Eventos hipóxicos e anóxicos têm sido relacionados ainda à etiologia de uma série de desordens psiquiátricas, incluindo esquizofrenia e autismo (BRIXLEY et al., 1993; CANNON et al., 2002).

Dentre os fatores de risco para a hipóxia ou anóxia pré, peri ou pós-natais citam-se a falta de cuidados pré-natais, estado nutricional materno deficiente, hemorragia pré-natal, toxemia materna (MAJEED et al., 2007), infecções do neonato, más formações congênitas, baixo peso ao nascimento, apresentação fetal anômala, parto prolongado e difícil, septicemia, hiperbilirrubinemia, meningoencefalites bacterianas ou virais, complicações obstétricas e mecânicas, pós-maturidade e prematuridade (BALADI et al., 2007). 
A prematuridade constitui importante fator de risco para a hipóxia/anóxia ao nascimento (GLUCKMAN et al., 2001). Os pulmões dos neonatos prematuros extremos (2426 semanas) estão em estágio de desenvolvimento diferente dos pulmões dos nascidos a termo. Neste estágio, o pulmão está apenas começando a ser viável para trocas gasosas. Deste modo, o parto prematuro e o início da respiração interrompem o desenvolvimento normal dos alvéolos e da vascularização pulmonar destas crianças. Os pulmões de prematuros ainda são geralmente deficientes em surfactantes, tornando-os mais predispostos a complicações respiratórias (SUGUIHARA et al., 2005).

Pesquisas mostram que apesar do sistema nervoso central imaturo apresentar maior tolerância a eventos hipóxicos (VOLPE, 1992; DELL'ANNA et al., 1993; NAKAJIMA et al., 1996; NAKAJIMA, 1999), há janelas de períodos críticos, onde o encéfalo está mais vulnerável e os neurônios em desenvolvimento estão particularmente mais suscetíveis ao insulto hipóxico ou outras influências ambientais nocivas, que podem influenciar negativamente em sua maturação (NYAKAS et al., 1996).

A teoria do período vulnerável foi introduzida por Dobbing (1968), que propôs que o encéfalo está mais vulnerável a insultos nas fases de grande e rápido crescimento celular. $\mathrm{O}$ primeiro período crítico ocorre durante a multiplicação e organização iniciais de neuroblastos que, nos mamíferos, acontece no período pré-natal (MORGANE et al., 1993). O segundo período crítico ocorre na fase de aleitamento do rato (WINICK e NOBLE, 1966), quando há rápido crescimento do encéfalo, com migração e diferenciação neuronais, sinaptogênese, multiplicação glial e mielinização evidentes (DOBBING, 1970; MORGANE et al., 1993; MANHÃES DE CASTRO et al., 2001).

A seqüência correta e ordenada da migração celular e a formação de uma microarquitetura apropriada podem definir períodos críticos adicionais, uma vez que, para adequado funcionamento encefálico, é fundamental o crescimento de processos neuronais, como axônios e dendritos, e o estabelecimento adequado de suas interconexões sinápticas ao alvo e células de projeção, respectivamente (NYAKAS et al., 1996).

As consequiências anatômicas da privação de oxigênio nos neurônios em desenvolvimento variam da morte celular à diferenciação prejudicada de extremidades celulares, como dendritos e axônios. Neurônios imaturos que sobrevivem ao insulto hipóxico agudo podem ainda ter comprometimento da formação de sinapses e crescimento de neuritos. Estas aparentemente mínimas anormalidades anatômicas podem ser base de disfunções comportamentais e psicológicas descritas anteriormente (NYAKAS et al., 1996). 
A patofisiologia da maioria das desordens comportamentais decorrentes da hipóxia/anóxia neonatal, como o TDAH e distúrbios de memória espacial e aprendizagem, está associada a alterações do funcionamento monoaminérgico central (RASKIN et al., 1984; HERLENIUS e LAGERCRANTZ, 2001).

\subsection{Anóxia e sistema monoaminérgico}

Neurotransmissores como as monoaminas aparecem no embrião antes dos neurônios estarem diferenciados e podem ter outras funções além da neurotransmissão, como diferenciação e crescimento neuronal. As funções dos sistemas de neurotransmissores no encéfalo em desenvolvimento podem ser alvo do insulto hipóxico ou anóxico, provavelmente ocasionando déficits comportamentais (NYAKAS et al., 1996).

O oxigênio molecular é o substrato para a ação das enzimas tirosina e triptofanohidroxilase, envolvidas na síntese das catecolaminas (dopamina, norepinefrina e epinefrina) e das indolaminas (serotonina), tornando-as particularmente susceptíveis aos efeitos da hipóxia (DAVIS et al., 1973).

Dentre as monoaminas, podemos destacar a serotonina (5-hidroxitriptamina ou 5-HT), que já pode ser encontrada no ovo fertilizado e está envolvida na morfogênese precoce do coração, epitélio craniofacial e outras estruturas. Se o embrião desenvolve-se em cultura, na presença de inibidores da recaptação de 5-HT, malformações craniais específicas ocorrem. As células serotoninérgicas na rafe estão dentre as primeiras a serem geradas no encéfalo (entre E11 e E15 no rato e entre a $5^{\mathrm{a}}$ e a $12^{\mathrm{a}}$ semanas no feto humano). Estas células enviam axônios ao córtex frontal e podem ter importância na diferenciação de progenitores neurais. (LAUDER et al., 1994).

A enzima tirosina hidroxilase pode ser detectada no primeiro dia de incubação da galinha, dopamina no segundo dia e a epinefrina no terceiro dia (PENDLETON et al., 1998). A norepinefrina é essencial para o desenvolvimento normal do encéfalo. O sistema noradrenérgico regula o desenvolvimento das células de Cajal-Retzius, que são os primeiros neurônios a se formar no córtex (NAQUI et al., 1999). A depleção de norepinefrina no período perinatal resulta em alterações dendríticas e possivelmente em alterações da diferenciação cortical (BERGER-SWEENEY e HOHMANN, 1997).

A dopamina tem papel fundamental na programação motora e cognitiva. Em humanos, os neurônios dopaminérgicos aparecem precocemente (6 a 8 semanas de desenvolvimento) (SUNDSTROM et al., 1993). Disfunções no desenvolvimento do sistema dopaminérgico 
podem ocasionar discinesia, distonia, tiques, transtorno obsessivo-compulsivo e movimentos oculares anormais (HERLENIUS e LAGERCRANTZ, 2001).

A anóxia exacerba a transmissão de sinais químicos na sinapse, causando não só distúrbios na neurotransmissão como também modulando o posterior desenvolvimento desses neurônios. Estudos mostram que neurônios em desenvolvimento utilizam neurotransmissores para construir não somente conexões funcionais, mas também promover diferenciação morfológica dentro do mesmo circuito funcional. Estas atividades neuronais envolvem interrelação entre eventos celulares e moleculares pré e pós-sinápticos que possuem importante plasticidade. Assim, tanto funções pré como pós-sinápticas podem ser influenciadas e distorcidas como conseqüência de insulto hipóxico (NYAKAS et al., 1996), levando a seqüelas comportamentais (HERLENIUS e LAGERCRANTZ, 2001).

Embora as consequiências da hipóxia/anóxia neonatal tenham sido extensivamente investigadas, as cascatas por elas desencadeadas dos processos patofisiológicos levando a disfunções neurológicas a longo prazo não parece ter sido bem documentada ainda (CHEN et al., 2007) e as áreas neurais envolvidas nessas respostas homeostáticas não estão identificadas.

\subsection{Controle neural da respiração}

A regulação da ventilação é vital para a sobrevivência. A respiração é um processo rítmico inconsciente gerado automaticamente por neurônios localizados no tronco encefálico, chamados gerador central de padrão (SILVERTHORN, 2003).

Informações sobre o grau de distensão dos alvéolos pulmonares continuamente são levadas aos núcleos do trato solitário pelas fibras aferentes viscerais gerais do nervo vago, passando em seguida para os centros respiratórios descritos a seguir, de onde saem fibras retículo-espinhais que terminam fazendo sinapse com neurônios motores da porção cervical da medula, que originam fibras que se dirigem ao diafragma, e da porção torácica, cujas fibras inervam os músculos intercostais. Estas vias são importantes para a manutenção reflexa ou automática dos movimentos respiratórios (MACHADO, 2004; LEVITZKY, 2004).

O gerador central de padrão respiratório é composto por 3 grupos de neurônios localizados bilateralmente no bulbo e na ponte: grupo respiratório dorsal, grupo respiratório ventral e grupo respiratório pontino (HALL e GUYTON, 2002) (Figura 1).

O grupo dorsal de neurônios respiratórios desempenha o papel mais importante no controle da ventilação (HALL e GUYTON, 2002). Estão localizados bilateralmente no núcleo 
do trato solitário, sendo constituídos por neurônios inspiratórios que aferentam principalmente a medula espinhal contralateral, e provavelmente servem como os principais iniciadores da atividade dos nervos frênicos, sendo responsáveis pela manutenção da atividade do diafragma (FINLEY e KATZ, 1992; LEVITZKY, 2004). O grupo dorsal é formado por duas populações de neurônios inspiratórios, as células I $\alpha$ e I $\beta$, e um terceiro grupo, denominado célulasbomba, constituída por interneurônios envolvidos na retransmissão da atividade aferente de receptores de estiramento pulmonares (LEVITZKY, 2004).

Os grupos respiratórios ventrais, localizados bilateralmente no núcleo retrofacial, no núcleo ambíguo e no núcleo retroambíguo, têm a função de estimular neurônios respiratórios medulares que inervam principalmente os músculos intercostais e abdominais ou músculos da respiração inervados pelos nervos vagos. Os neurônios do núcleo ambíguo são principalmente motoneurônios vagais que inervam os músculos ipsilaterais laríngeos, faríngeos e da língua envolvidos na respiração e na manutenção da permeabilidade das vias aéreas superiores. São neurônios inspiratórios e expiratórios. No núcleo retroambíguo, as células inspiratórias parecem estar localizadas mais cefalicamente e as células expiratórias estão localizadas mais caudalmente. O núcleo retrofacial, localizado mais cefalicamente nos grupos respiratórios ventrais, contém principalmente neurônios expiratórios em um grupo de células denominado complexo de Bötzinger, os quais inibem as células inspiratórias do grupo respiratório dorsal e também alguns motoneurônios frênicos. As células do complexo pré-Bötzinger, localizado caudalmente ao complexo de Bötzinger, atuam como marcapassos estabelecendo o ritmo respiratório (LEVITZKY, 2004; SIMAKAJORNBOON e KUPTANON, 2005).

O centro pneumotáxico, atualmente chamado de grupos respiratórios pontinos, está localizado na porção superior da ponte, no núcleo parabraquial medial e no núcleo de Kölliker-Fuse e atuam modulando o padrão respiratório (LEVITZKY, 2004), limitando a duração da inspiração e aumentando a frequiência ventilatória (HALL e GUYTON, 2002). Os grupos respiratórios pontinos também podem modular a resposta do sistema de controle respiratório a outros estímulos, como na hipercapnia e na privação de oxigênio (LEVITZKY, 2004). 

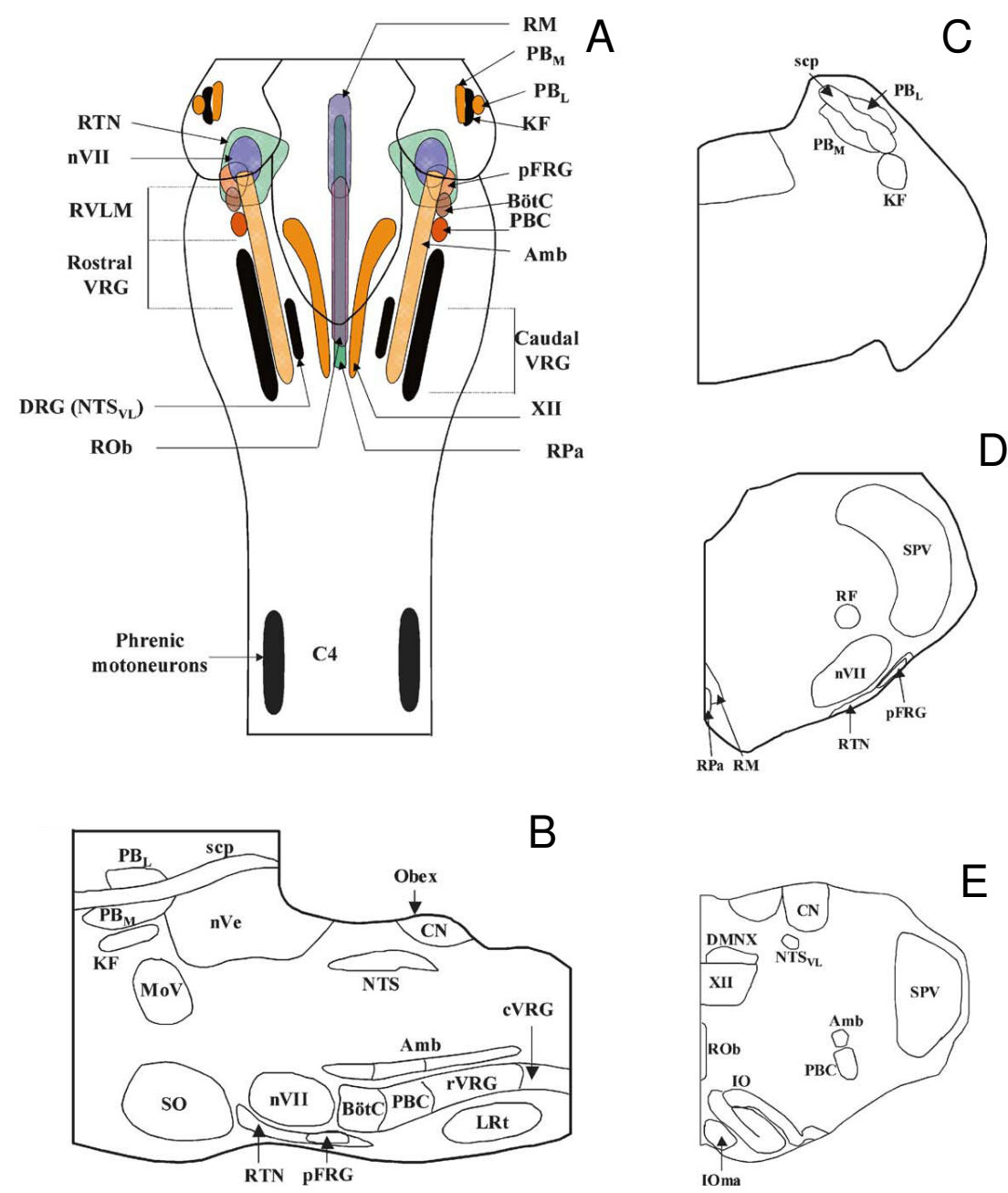

Figura 1. Representação esquemática dos núcleos do tronco encefálico que participam do controle respiratório. (A) Representação longitudinal esquemática dos núcleos do tronco encefálico associados ao controle respiratório. Amb: núcleo ambíguo; BötC: complexo de Botzinger; DRG: grupo respiratório dorsal; KF: núcleo de Kölliker-Fuse; NTS: núcleos do trato solitário; RM, núcleo magno da rafe; PBC: complexo pre-Bötzinger complex; PBL: núcleo :parabrachial lateral; PBM: núcleo parabraquial medial; pFRG: grupo respiratório parafacial; ROb: núcleo obscuro da rafe; RVLM: medula rostroventrolateral; VRG: grupo respiratório ventral; XII: núcleo do nervo hipoglossal. C4: nível da 4a. Vértebra cervical; nVII: núcleo facial. (B) Representação parassagital esquemática dos núcleos respiratórios do tronco encefálico. LRt: núcleo reticular lateral; RTN: núcleo retrotrapezóide; $\mathrm{CN}$ : núcleo cuneado; MoV: núcleo motor do nervo trigêmeo; nVe: núcleo vestibular; SO: núcleo olivar superior. (C)-(E) Representação esquemática de secções coronais do tronco encefálico do rato na ponte (C); medula rostral (D); medula caudal (E) DMNX: núcleo motor dorsal do vago; IO: núcleo olivar inferior; IOma: núcleo olivar acessório medial; RF: núcleo retrofacial; scp: pedúnculo cerebelar superior; SPV: núcleo espinal do nervo trigêmeo. 
Os grupos respiratórios recebem informações de vários receptores, como por exemplo: receptores de adaptação lenta, que sinalizam o estiramento pulmonar, receptores de adaptação rápida, localizados na traquéia, brônquios e bronquíolos; receptores do nariz e vias aéreas superiores e quimiorreceptores (GANONG, 2006).

Os quimiorreceptores podem ser divididos em periféricos e centrais (GANONG, 2006). Os periféricos compreendem os corpos carotídeos, localizados bilateralmente na bifurcação da artéria carótida comum, e os corpos aórticos, localizados ao redor das porções proximais da aorta. São sensíveis às variações de pressão do oxigênio, gás carbônico e ao pH do sangue arterial (GANONG, 2006).

A localização dos quimiorreceptores centrais ainda não está totalmente elucidada. Supõe-se que estão localizados difusamente no sistema nervoso central, em regiões como o cerebelo, hipotálamo posterior, várias áreas do tronco encefálico, principalmente núcleos da rafe (RICHERSON, 2004), locus coeruleus (PUTNAM et al., 2004), núcleos do trato solitário, núcleo retrotrapezóide (MULKEY et al., 2004) e áreas próximas à superfície ventral da medula (NATTIE, 2001). Estes quimiorreceptores não são sensíveis às variações na concentração de oxigênio, mas são bastante sensíveis às variações de gás carbônico e de pH (GANONG, 2006).

Neuromoduladores possuem diversas funções no controle da atividade rítmica respiratória, geralmente regulando a amplitude e a freqüência da atividade respiratória. Agem em motoneurônios, neurônios sensoriais e naqueles localizados em diversos núcleos do sistema nervoso central (DOI e RAMIREZ, 2008). Alguns estão envolvidos na geração e transmissão do ritmo respiratório, como o glutamato, ácido $\gamma$-amino-butírico (GABA), glicina e 5-HT (BONHAM, 1995).

Estudos relacionam a 5-HT como importante modulador do ritmo respiratório (BONHAM, 1995), sendo proposto que, sob condições em que o oxigênio metabólico é necessário em demanda excessiva, como numa hipóxia, 5-HT pode ser liberada no SNC para promover o ritmo respiratório normal (LALLEY et al., 1994).

A 5-HT, a dopamina e norepinefrina exercem efeitos tanto inibitórios como excitatórios (DOI e RAMIREZ, 2008). A dopamina e a norepinefrina também participam da integração do controle cárdio-pulmonar (HEDNER, 1983). GABA e glicina são os principais neurotransmissores inibitórios na rede de neurônios respiratórios (HAJI et al., 2000). 


\subsection{Resposta à privação de oxigênio e morte celular}

Numa primeira etapa, o organismo reage à privação de oxigênio tentando manter as funções celulares o mais próximo da normalidade possível. Em seguida, esgotadas as possibilidades energéticas, as cascatas desencadeadas acabam levando à falência deste sistema de proteção, culminando em morte celular.

\subsubsection{Mecanismos moleculares envolvidos na resposta à privação de oxigênio}

A resposta ventilatória à hipóxia/anóxia é originária de quimiorreceptores periféricos (corpos carotídeos e corpos aórticos) os quais exercem influência excitatória sobre o controlador respiratório central, ativando mecanismos para aumentar a demanda de oxigênio, através do aumento da ventilação pulmonar, do trabalho cardíaco e da perfusão tecidual (LUTZ e PRENTICE, 2002). Nesta situação, os corpos carotídeos são muito mais atuantes, já que os corpos aórticos são incapazes de sustentar a resposta ventilatória numa privação de oxigênio (LEVITZKY, 2004).

Estudos demonstram que resposta ventilatória à hipóxia está relacionada com a alteração da pressão parcial de oxigênio $\left(\mathrm{PO}_{2}\right)$ e não à alteração do conteúdo de oxigênio (LEVITZKY, 2004). Nos mamíferos, a resposta ventilatória à hipóxia é bifásica, consistindo de aumento inicial na ventilação-minuto seguido por declínio na ventilação, o qual é chamado de depressão hipóxica ventilatória (VIZEK et al., 1987; POWELL et al., 1998). Esta resposta é um processo complexo, em que vários componentes excitatórios, inibitórios e modulatórios estão envolvidos (LIU et al., 2006) (Figura 2).

Pesquisas mostram que a resposta primária à hipóxia no tronco encefálico caudal de ratos adultos é mediada pelos receptores glutamatérgicos $N$-metil-D-aspartato (NMDA) (OHTAKE et al., 1998; WHITNEY et al., 2000; VEXLER e FERRIERO, 2001), cuja ativação envolve o recrutamento das vias intracelulares da proteína kinase $C$ (PKC) e do óxido nítrico sintase neuronal (nNOS) (GOZAL et al., 2000a; VEXLER e FERRIERO, 2001; REEVES e GOZAL, 2007). A ativação dos receptores NMDA induz ainda a ativação dos fatores de transcrição dos genes de expressão imediata ("immediate early genes" - IEGs), como $c$-fos e $c$-jun, do fator nuclear kappa B (NF-kB) e da proteína $h s p 70$ ("heat shock protein 70”). O significado funcional da expressão tanto da $h s p 70$ como dos IEGs não está totalmente esclarecido; o que se pode afirmar é que possuem relação com eventos que 
promovem tanto a recuperação celular como os que levam à morte celular (GILBY et al., 1997).

A segunda fase da resposta ventilatória à hipóxia, a depressão hipóxica ventilatória, envolve vários mecanismos, dos quais participam neuromoduladores como a adenosina (ELNAZIR et al., 1996; BARROS et al., 2000; GOURINE et al., 2005; BARROS et al., 2006), GABA (GENEST et al., 2007; HEHRE et al., 2008), opióides (XIA e HADDAD, 1991; TEICHTAHL et al., 2005; MODALEN et al., 2006), receptores de fatores de crescimento plaqueta-derivados (PDGF- $\beta$ ) (GOZAL et al., 2000b; VLASIC et al., 2001; LIU et al., 2005; BAVIS, 2005) e serotonina (DI PASQUALE et al., 1992; MCGUIRE et al., 2003; GARGAGLIONI et al., 2006; TRYBA et al., 2006), somados ao hipometabolismo hipóxico (MORTOLA, 1999). Estudos recentes indicam que, no núcleo do trato solitário de porcos jovens, a depressão hipóxica ventilatória é mediada ainda por aminoácidos inibitórios, glicina e taurina (HEHRE et al., 2008).

A depressão hipóxica ventilatória difere entre o neonato e o adulto. Em mamíferos neonatos expostos à hipóxia prolongada, a ventilação-minuto diminui gradualmente a níveis próximos ou inferiores àqueles observados na normóxia (COHEN et al., 1997), enquanto no mamífero adulto a depressão hipóxica ventilatória mostra uma diminuição da ventilaçãominuto a níveis que permanecem ainda mais elevados que o basal (GERSHAN et al., 1994; MAXOVÁ e VÍZEK, 2001).

A resposta crônica à hipóxia é mediada pelo fator de transcrição induzido pela hipóxia 1 (em inglês HIF-1- hypoxia-inducible family 1) alpha e beta (SEMENZA, 2000; CHOWDHURY et al., 2008). O HIF-1 é o mais importante mediador de respostas celulares e moleculares à hipóxia, sendo responsável pela manutenção da homeostase de oxigênio. No encéfalo, mecanismos regulados pela HIF-1 estão envolvidos nas respostas adaptativas à hipóxia focal e global (FANDREY et al., 2006). 


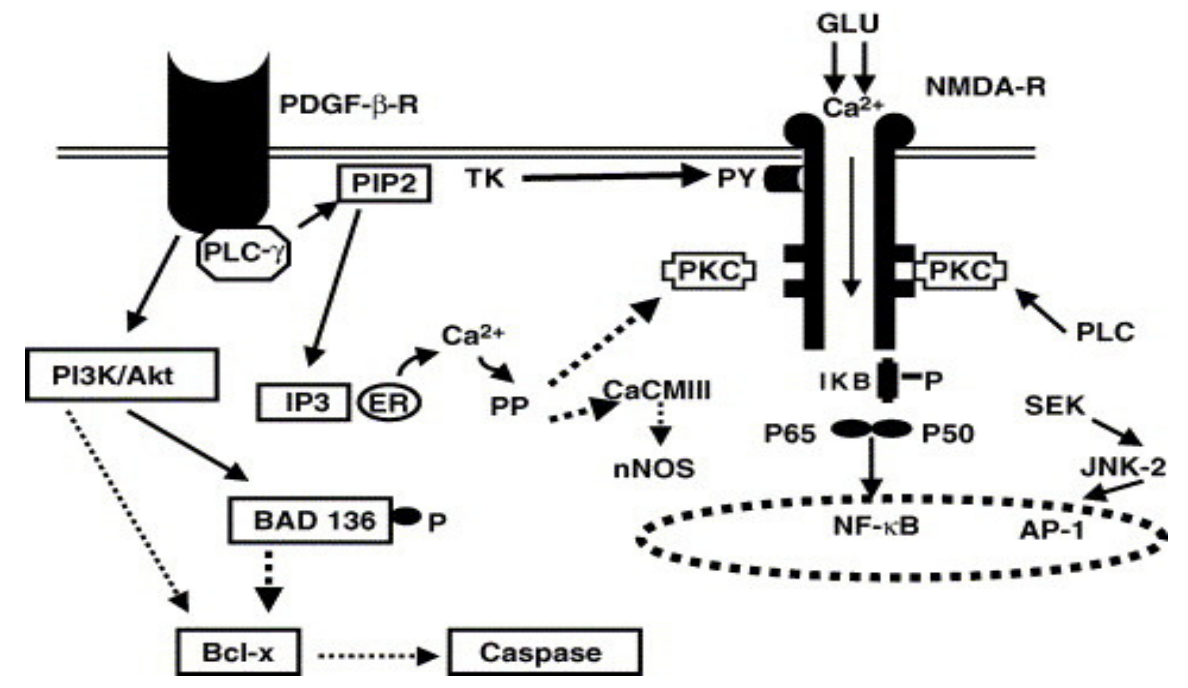

Figura 2. Resposta ventilatória à hipóxia. Durante a primeira fase de resposta à hipóxia, a ativação do receptor glutamatérgico NMDA (NMDA-R) causa influxo de cálcio e subseqüente ativação da fosfolipase C (PLC), da proteína quinase mitogene-ativada (SEK) e da cálcio-calmodulina quinase 2 (CaCmII). A ativação da PLC leva à translocação da proteína quinase $\mathrm{C}$ e fosforilação dos resíduos de serina e trreonina no domínio intacelular dos NMDA-R. A SEK fosforila a proteina quinase 2 ativada pelo estresse (JNK-2) levando à ativação do complexo ativador da proteína 1 (AP-1). CaCmII ativa a óxido nítrico sintase neuronal resultando na formação de óxido nítrico. A ativação do NMDA-R também leva à fosforilaçao de I $\mathrm{B}$ com subseqüente ativação do fator nuclear kappa $\mathrm{b}(\mathrm{NF}-\kappa \mathrm{B})$ e ativação da tirosina quinase (TK) pela fosforilação da tirosina (PY). Durante a segunda fase de resposta à hipóxia, a liberação de PDGF-BB subseqüente ativação de receptores PDGF- $\beta$ ativam a fosfolipase C-y (PLC-y) que, por sua vez, ativa o trifosfato fosfoinositol (IP3). O IP3 ativa a proteína fosfatase (PP) e então desfosforila as isoformas da proteína quinase $\mathrm{C}$ sob ativação dos NMDA-R, diminuindo a atividade de seus canais e resultando na depressão hipóxica ventilatória. A fosforilação dos receptores PDGF- $\beta$ também levam à ativação de PI3K/Akt e subseqüiente fosforilação de BAD especialmente serina 136. $\mathrm{BAD}$ fosforilado irá impedir a ligação entre $\mathrm{BAD}$ e Bcl-x, levando à inativação da caspase.

FONTE: GOZAL et al., 2000a

\subsubsection{Aspectos moleculares da morte celular após privação de oxigênio}

O encéfalo é extremamente sensível a reduções no suprimento de oxigênio; esta vulnerabilidade deve-se a seu alto consumo energético, que não pode ser comprometido (LUTZ e PRENTICE, 2002).

A privação de oxigênio dispara uma cascata de eventos bioquímicos que ocorrem quase que simultaneamente (VEXLER e FERRIERO, 2001). Esta cascata envolve: interrupção do metabolismo energético, desequilíbrio ácido-básico, acúmulo de espécies oxigênio-reativas e de aminoácidos excitatórios no espaço extracelular, perda do equilíbrio de água celular e início da apoptose (ENGIDAWORK et al., 1997; VEXLER e FERRIERO, 2001). Estes eventos são rápidos e de curta duração, assim, o espaço de tempo para intervenções terapêuticas é bastante reduzido (ENGIDAWORK et al., 1997). 
A depleção de ATP tem importantes conseqüências, incluindo falha no funcionamento das bombas iônicas de sódio-potássio, ativação da formação de radicais livres (COHEN, 1973; DELL'ANNA et al., 1997; LOIDL et al., 2000), mudanças no estado de fosforilação de diferentes enzimas e proteínas estruturais (LIPTON, 1999). A falha nas bombas iônicas permite a passagem de íons através da memebrana abaixo dos gradientes de concentração. A despolarização anóxica resultante leva a uma cadeia de conseqüências letais (LUTZ et al., 2002). Seguinte à despolarização, há perda massiva de neurotransmissores como glutamato, aspartato e dopamina para o espaço extracelular em quantidade tóxica (LIPTON, 1999). Há ainda excessiva liberação de dopamina levando à lesão tecidual (GLOBUS et al., 1988). O aumento descontrolado de cálcio intracelular parece ser particularmente nocivo, ocasionando efeitos múltiplos disfuncionais dentre os quais estimulação de hidrólise fosfolipídica, com aumento da formação de radicais livres (LUTZ et al., 2002).

Estas mudanças induzem lesão ou morte das células mais vulneráveis do sistema nervoso central, primariamente localizadas no hipocampo (uma das regiões cerebrais mais sensíveis à anóxia) (BUWALDA, 1995), no córtex cerebral e núcleos basais (mais susceptíveis a lesões no último trimestre de gestação); estas áreas estão envolvidas em funções cognitivas (aprendizado e memória) e funções motoras (LOIDL et al., 2000; CIRULLI, 2003).

Pesquisas têm mostrado maior esclarecimento a respeito dos aspectos celulares e moleculares da neurodegeneração no encéfalo imaturo, especialmente características que o tornam diferente quando comparado à lesões semelhantes no encéfalo adulto. Sugere-se que a neurodegeneração se estenda por dias ou semanas seguintes ao insulto e seja muito influenciada por receptores, enzimas proteolíticas e mecanismos programados de morte celular que são altamente expressos durante o desenvolvimento (JOHNSTON et al., 2002).

Estudos mostram que a lesão primária após insulto hipóxico-isquêmico em fetos e neonatos ocorre devido à necrose celular, enquanto a lesão secundária, após horas ou dias, é decorrente de apoptose ou morte celular programada (BEILHARZ et al., 1995; EDWARDS et al., 1997; NAKAJIMA et al., 2000; NORTHINGTON et al., 2001). As caspases, pertencentes a superfamília de proteases aspartil-específicas, em especial a Caspase-3, têm um papel importante na neurodegeneração após episódio hipóxico-isquêmico (SCHULZ et al., 1999).

Maior conhecimento é necessário para definir a contribuição dos eventos citados à disfunção e morte neuronais e, em particular, para determinar parâmetros úteis para predizer a gravidade do insulto hipóxico-isquêmico ou anóxico e seus resultados a curto e longo prazos. Marcadores celulares, neste caso marcadores neuronais, representam ferramentas úteis para o 
estudo das regiões envolvidas com a anóxia neonatal no encéfalo e auxiliar na compreensão dos mecanismos descritos. Neste trabalho, escolhemos como marcador nuclear a proteína Fos, a fim de evidenciar áreas ativadas agudamente com a anóxia.

\subsection{Proteína Fos}

A proteína Fos é uma fosfoproteína traduzida a partir do gene c-fos (BREEN et al., 1997), que pertence ao grupo de genes de transcrição rápida, cujo produto protéico age diretamente alterando a expressão gênica e levando a respostas fenotípicas alternativas. Devido ao fato de sua expressão após o aparecimento do estímulo ser rápida e transitória e pela ativação da transcrição não depender da síntese de proteínas, tais genes são denominados genes de expressão imediata (MORGAN e CURRAN, 1989, 1991; SHENG e GREENBERG, 1990; HERSCHMAN, 1991; BREEN et al., 1997).

O c-fos é um protooncogene nuclear c erbA (WEINBERGER et al., 1986), homólogo celular do gene transformador ( $\mathrm{v}-f o s)$ dos vírus do sarcoma de roedores FBJ e FBR (CURRAN et al., 1983; FINKEL et al., 1966; VAN BEVEREN et al., 1983), daí a origem do nome fos - "Finkel-Biskis-Jinkis murine osteogenic sarcoma vírus" (FBJ-MSV). É o principal representante de uma família de genes de expressão imediata que compreende FRA-1, FRA-2 e fosB (COHEN e CURRAN, 1988; ZERIAL et al., 1989; NISHINA et al., 1990).

O produto protéico do gene c-fos é uma proteína nuclear que contém 3 domínios importantes: uma região de regulação da transcrição, uma região zíper de leucina (LANDSCHULZ et al., 1988) e uma região de ligação de DNA (NAKABEPPU e NATHANS, 1989). Estas características da proteína Fos e a sua participação no complexo de ativação de transcrição AP-1 permitem que ela influencie a transcrição de diferentes genes de expressão secundária (LEE et al., 1987). O fator de transcrição AP-1 é um dos reguladores da transcrição direta do gene em resposta a estímulos tanto fisiológicos como patológicos. É composto por heterodímeros da família de proteínas Jun (c-Jun, JunB, JunD) e Fos (c-Fos, FosB, FRA-1 e FRA-2) ou homodímeros da família de proteínas Jun (ANGEL e KARIN, 1991; ERIKSSON et al., 2007).

Estudos mostram que os níveis basais do RNA mensageiro (RNAm) do gene c-fos e de seu produto, a proteína Fos, na maioria dos tipos celulares, são relativamente baixos. Um grande número de estímulos extracelulares é capaz de induzir aumento rápido e transitório do RNAm do gene c-fos (HERSCHMAN, 1991; MORGAN e CURRAN, 1991). A indução da expressão do gene c-fos no sistema nervoso está associada a agentes que causam 
despolarização e aumento da atividade neuronal (BREEN et al., 1997). A ativação da transcrição ocorre rapidamente (em minutos) e o acúmulo tanto do RNAm como da proteína Fos têm sido bastante utilizados como indicadores da ativação neuronal e como meio de identificar mecanismos envolvidos na resposta de estímulos específicos (DRAGUNOW e FAULL, 1989). A ativação da transcrição ocorre dentro de 5 minutos e continua por 15 a 20 minutos (GREENBERG e ZIFF, 1984; GREENBERG et al., 1985). O RNAm se acumula e alcança o pico de seu valor entre 30 e 45 minutos após o estímulo (MULLER et al., 1983), declinando a partir de então dentro de aproximadamente 12 minutos. A síntese da proteína Fos segue à expressão do RNAm e possui uma meia-vida de cerca de 2 horas (MULLER et al., 1984; CURRAN et al., 1984).

A seguinte sequiência de estímulos culmina com a produção de Fos: estímulos extracelulares abrem canais de cálcio fazendo com que estes íons entrem na célula e ativem a CaM (Ca ++/calmodulina) quinase II, que é responsável pela fosforilação do fator de transcrição CREB (“cAMP - response element binding protein”, ou seja, proteína de ligação responsiva ao cAMP). O CREB possui um motivo de ativação pela fosforilação e um motivo responsável pela ligação ao DNA. Portanto, ao ser ativado via cAMP o CREB se liga a uma seqüência reguladora de DNA, o CRE, iniciando a transcrição dos genes de expressão precoce c-fos e jun B, produzindo as proteínas Fos e Jun. Essas possuem um motivo zíper de leucina, o qual é composto por uma região com aproximadamente 30 aminoácidos caracterizada por repetições de leucina a cada 7 aminoácidos. Os motivos de leucina de 2 proteínas formam dímeros com alfa-hélices paralelas. Assim, a dimerização da Fos e da Jun formam um heterodímero, o complexo AP-1 de ligação. Essa manobra amplia as chances de combinação de domínios de ativação e repressão. Assim, várias porções do DNA que contenham o sítio específico para este fator são ativados, regulando a síntese de neurotransmissores positiva ou negativamente (GOLOMBEK e RALPH, 1996) (Figura 3).

Estudos demonstraram que uma variedade de tratamentos experimentais, como lesões, atividades explosivas, depressão ou traumas (ADEN, 1994), promovem ativação neuronal e consequente expressão da proteína Fos ou do RNAm c-fos. A administração de antagonistas de aminoácidos excitatórios atenua esta expressão (ADEN, 1994). A expressão do gene c-fos pode ainda refletir a ativação de padrões neuronais relacionados à lesão celular neuronal após hipóxia e/ou isquemia (ADEN, 1994).

Estudos evidenciaram que hipóxia sistêmica moderada em coelhos ou ratos conscientes resultam em altos níveis de expressão de c-fos em várias regiões do tronco encefálico inferior, como núcleo do trato solitário, medula rostro ventrolateral, medula 
intermédia ventrolateral, medula caudo ventrolateral, área A5, complexo parabraquial, locus ceruleus e região subcerúlea e em regiões suprapontinas, incluindo a substância cinzenta periaquedutal e vários núcleos hipotalâmicos (núcleo dorsomedial, núcleo posterior, núcleo paraventricular, núcleo supraóptico e núcleo arqueado) (ERICKSON e MILLHORN, 1994; SMITH et al.,1995; HIROOKA et al., 1997; BULLER et al., 1999; BERQUIN et al., 2000).

Redução imediata dos níveis de proteína Fos tem sido observada após períodos extensivos de anóxia em ratos adultos e em ratos jovens. Em contraste, a expressão de RNAm c-fos aumenta após condições de suprimento reduzido de oxigênio ou circulação sanguínea deficitária tanto em animais adultos como em desenvolvimento. O metabolismo energético é muito prejudicado sob condições anóxicas e uma inibição prolongada da síntese da proteína Fos foi observada após insultos anóxicos ou isquêmicos no hipocampo de animais jovens e adultos (DELL'ANNA et al., 1995a).

O gene c-fos é ativado após hipóxia isquêmica neonatal e estudos sugerem que a proteína Fos pode gerar ou intensificar a morte neuronal celular decorrente de isquemia e lesão encefálica traumática (ADEN, 1994), apesar de outros autores mostrarem que a produção da proteína Fos não é obrigatoriamente relacionada com morte celular após lesão hipóxico-isquêmica neonatal (OORSCHOT et al., 2000). 


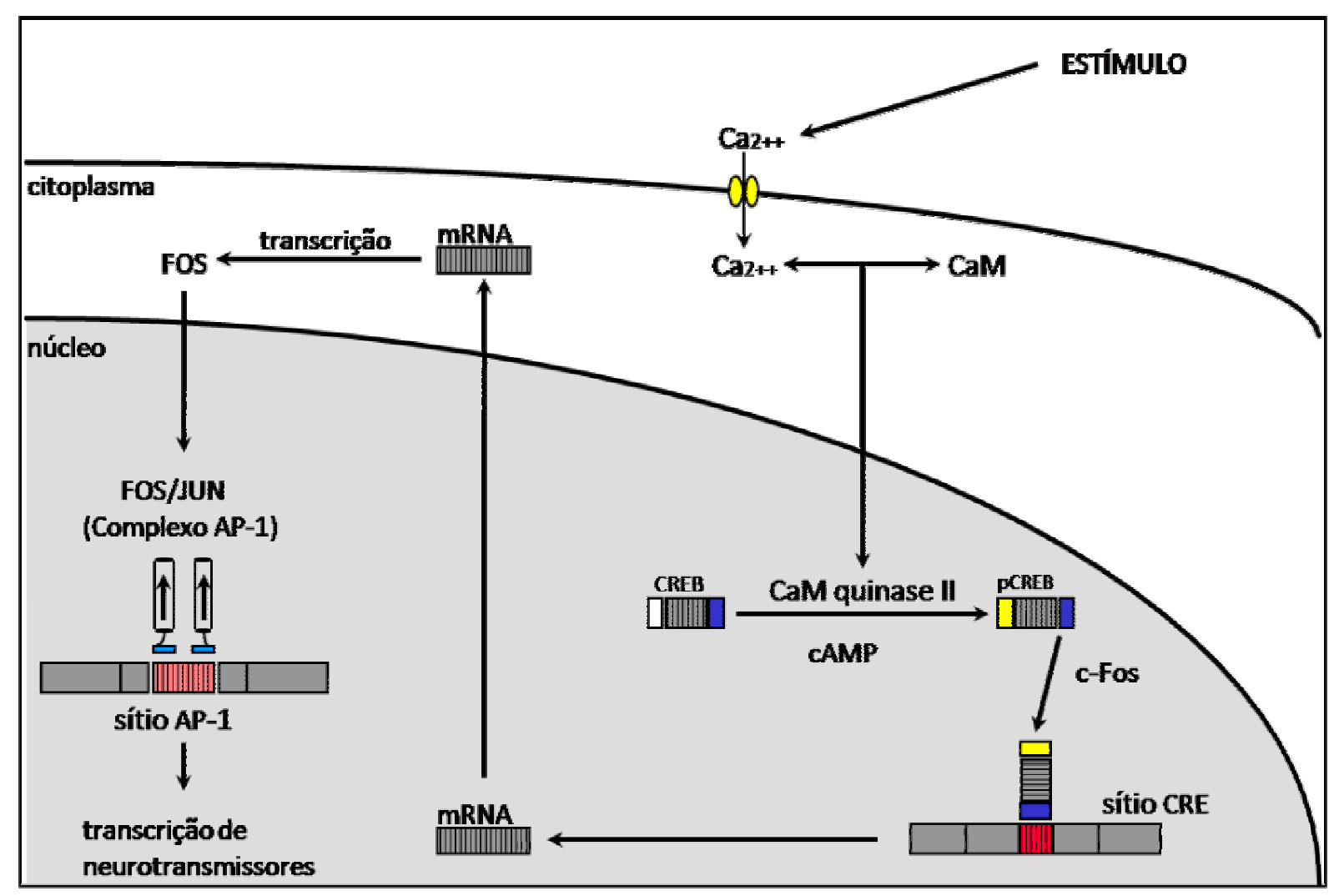

Figura 3. Vias intracelulares que levam à formação das proteínas Fos e Jun. O receptor é estimulado e abre os canais de $\mathrm{Ca}^{++}$, este no citoplasma ativa a enzima $\mathrm{Ca}$ /calmodulina $(\mathrm{CaM})$ quinase II, que então fosforila o fator de transcrição CREB, que por sua vez induz a expressão do proto-oncogen c-fos ao se ligar ao sítio CRE do DNA. A proteína Fos produzida se dimeriza com outra proteína, a JUN, para formar o complexo AP-1, que irá regular a transcrição dos genes cujas estruturas tenham o sítio de ligação para o complexo AP-1.

FONTE: TAKASE, L.F. e NOGUEIRA, M.I., 1998; modificado de GOLOMBEK, D.A. e RALPH, M.R., 1996.

O estudo dos efeitos da hipóxia no encéfalo em desenvolvimento pode prover melhor compreensão dos processos patofisiológicos básicos necessários para a sobrevivência de células do encéfalo e para a recuperação das funções celulares. A lesão neuronal aguda necessita de intervenção terapêutica própria e adequada para prevenir perda celular e para auxiliar na recuperação celular (NYAKAS et al., 1996). Desta forma, tem sido de grande interesse utilizar modelos animais para testar se alterações no nascimento podem levar a alterações nos sistemas monoaminérgicos (EL-KHODOR e BOKSA, 2003).

Estudos animais são importantes também para prover informações a respeito dos mecanismos da lesão cerebral hipóxico-isquêmica e como a lesão tecidual pode ser prevenida ou minimizada pela intervenção terapêutica (VANNUCCI et al., 1999) e vários modelos animais têm sido desenvolvidos para estudar em detalhes a patofisiologia da hipóxia perinatal e suas consequiências comportamentais (BUWALDA, 1995). O tratamento destas desordens 
deve considerar não somente a terapêutica para cada sintoma, mas a intervenção nos mecanismos envolvidos em sua patogênese (DELL'ANNA et al., 1997).

Há poucos dados em literatura a respeito da ativação de Fos no modelo de anóxia neonatal utilizado neste trabalho, não havendo, portanto, estudos que correlacionem a ativação de áreas encefálicas após anóxia neonatal com as suas seqüelas comportamentais e possíveis seqüelas motoras. Desta forma, faz-se necessário a identificação da distribuição das regiões ativadas no encéfalo após anóxia neonatal bem como sua interpretação funcional, a fim de compreender os eventos relacionados tanto à neurodegeneração como à neuroregeneração e, se possível, contribuir com novas abordagens e perspectivas terapêuticas. 


\section{CONCLUSÕES}

Considerando os resultados obtidos, podemos concluir que:

- o modelo experimental de anóxia neonatal utilizado é eficiente em produzir privação temporária de oxigênio no encéfalo dos neonatos, levando a respostas fisiológicas e metabólicas condizentes com a anóxia;

- a análise do número de células IR-Fos evidenciou que áreas encefálicas relacionadas ao controle da respiração foram ativadas no grupo Anóxia, reforçando a eficácia do modelo utilizado;

- foram ativadas populações neurais específicas em alguns núcleos envolvidos na regulação da respiração e no controle cárdio-vascular;

- a ausência de marcação em alguns núcleos relacionados à regulação respiratória e cárdio-vascular concordam com o padrão de maturação desses circuitos conforme hipotetizado na literatura

- a maior quantidade de neurônios IR-Fos observada em estruturas límbicas do grupo Anóxia em relação ao Controle sugerem relações entre o insulto anóxico e seqüelas neurocomportamentais envolvidas com lesões destas regiões, como por exemplo o déficit de memória espacial e aprendizagem;

- alguns núcleos da rafe, como os núcleos dorsal, núcleo magno, núcleo pálido e o núcleo obscuro apresentaram maior número de neurônios IR-Fos no grupo Anóxia quando comparados com o Controle, sugerindo atuação do sistema serotoninérgico no controle respiratório;

- esse estudo indica envolvimento de regiões encefálicas relacionadas às seqüelas da anóxia neonatal e abrem perspectivas de estudos para desenvolvimento de novas terapêuticas aos déficits motores, cognitivos e comportamentais. 


\section{REFERÊNCIAS*}

ÅDÉN, U.; BONA E.; HAGBERG H.; FREDHOLM B.B. Changes in c-fos mRNA in the neonatal rat brain following hypoxic ischemia. Neuroscience Letters, v. 180, p. 91-95, 1994.

AMARAL, D. G.; WITTER, M. P. In: PAXINOS, G. The rat nervous system. 2. ed. San Diego: Academic Press, 1995. p. 443-486.

ANGEL, P.; KARIN, M. The role of Jun, Fos and the AP-1 complex in cell-proliferation and transformation. Biochimica et Biophysica Acta, v. 1072, n. 2-3, p. 129-157, 1991.

BAKR, A. F.; HABIB, H. S. Normal values of pulse oximetry in newborns at high altitude. Journal of Tropical Medicine, v. 51, n. 3, p. 170-173, 2005.

BALADI, A. B. P. C.; CASTRO, N. M. D.; MARAIS FILHO, M. C. Paralisia cerebral. In: FERNANDES, A. C.; RAMOS, A. C. R.; CASAliS, M. E. P.; HEBERT S. K. (Ed.) AACD Medicina e Reabilitação: princípios e prática. São Paulo: Artes Médicas, 2007, p. 15-34.

BARROS, R. C.; BRANCO, L. G.; CÁRNIO, E. C. Respiratory and body temperature modulation by adenosine A1 receptors in the anteroventral preoptic region during normoxia and hypoxia. Respiratory Physiology \& Neurobiology, v. 153, n. 2, p. 115-125, 2006.

BAVIS, R. W. Developmental plasticity of the hypoxic ventilatory response after perinatal hyperoxia and hypoxia. Respiratory Physiology \& Neurobiology, v. 149, n. 1-3, p. 287-299, 2005.

BERGER-SWEENEY, J.; HOHMANN, C. F. Behavioral conequences of abnormal cortical development: insights into developmental disabilities. Behavioral Brain Research, v. 86, n. 2, p. 12142, 1997.

BEILHARZ, E. J.; WILLIAMS, C. E.; DRAGUNOW, M.; SIRIMANNE, E. S.; GLUCKMAN, P. D. Mechanisms of delayed cell death following hypoxic-ischemic injury in the immature rat: evidence for apoptosis during selective neuronal loss. Brain Research. Molecular Brain Research, v. 29, n. 1, p. $1-14,1995$.

BERQUiN, P.; CAYETANOT, F.; GROS, F.; LARNICOL, N. Postnatal changes in Fos-like immunoreactivity evoked by hypoxia in the rat brainstem and hypothalamus.Brain Research, v. 877, n. 2, p. 149-159, 2000.

BLOOM, S. L.; SWINDLE, R. G.; MCINTIRE, D. D.; LEVENO, K. J. Fetal pulse oximetry: duration of desaturation and intrapartum outcome. Obstetics \& Ginecology, v. 93, n. 6, p. 1036-1040, 1999.

BOHR, I. Hypercholesterolemic diet applied to rat dams protects their offspring against cognitive deficits. Simulated neonatal anoxia model. Physiology \& Behavior, v. 82, n. 4, p. 703-711, 2004.

BONHAM, A.C. Neurotransmitters in the CNS control of breathing. Respiratory Physiology, v. 101, p. 219-30, 1995.

BREEN, S.; REES, S.; WALKER, D. Identification of brainstem neurons responding to hypoxia in fetal and newborn sheep. Brain Research, v. 748, p. 107-121, 1997.

\footnotetext{
* De acordo com:

ASSOCIAÇÃO BRASILEIRA DE NORMAS TÉCNICAS. NBR 6023: Informação e documentação: referências: elaboração. Rio de Janeiro, 2002.
} 
BRIXLEY S.N.; GALLAGHER, B.J. $3^{\text {rd; }}$ MCFALLS, J.A.JR; PARMELEE, L.F. Gestacional and neonatal factors in the etiology of schizophrenia. Journal of Clinical Psychology, v.49, p. 447-456, 1993.

BULLER, K. M.; SMITH, D. W.; DAY, T. A. NTS catecholamine cell recruitment by hemorrhage and hypoxia. Neuroreport, v. 10, n. 18, p. 3853-3856, 1999.

BUWALDA, B.; NYAKAS, C.; VOSSELMAN, H.J.; LUITEN, P.G.M. Effects of early postnatal anoxia on adult learning and emotion in rats. Behavioural Brain Research, v. 67, p. 85-90, 1995.

CANNON, M.; JONES, P.B.; MURRAY, R.M. Cannon, M., Jones, P.B., Murray, R.M., Obstetric complications and schizophrenia: historical and meta-analyric review. American Journal of Psychiatry, v. 159, p. 1080-1092, 2002.

CAPUTA, M.; ROGALSKA, J.; WENTOWSKA, K.; NOWAKOWSKA, A. Perinatal asphyxia, hyperthermia and hyperferremia as factors inducing behavioural disturbances in adulthood: a rat model. Behavioral Brain Research, v. 163, n. 2, p. 246-256, 2005.

CASOLINI, P. ZUENA, A. R.; CINQUE, C.; MATTEUCCI, P.; ALEMÀ, G. S.; ADRIANI, W.; CARPINELLI, G.; SANTORO, F.; ALLEVA, E.; BOSCO, P.; NICOLETTI, F.; LAVIOLA, G.;

CATALANI, A. Sub-neurotoxic neonatal anoxia induces subtle behavioural changes and specific abnormalities in brain group-I metabotropic glutamate receptors in rats. Journal of Neurochemistry, v. 95 , n. 1, p. 137-145, 2005.

CHEN, W. F.; CHANG, H.; WONG, C. S.; HUANG, L. T.; YANG, C. H.; YANG, S. N. Impaired expression of postsynaptic density proteins in the hippocampal CA1 region of rats following perinatal hypoxia. Experimental Neurology, v. 204, n. 1, p. 400-410, 2007.

CHOWDHURY, R.; HARDY, A.; SCHOFIELD, C. J. The human oxygen sensing machinery and its manipulation. Chemical Society Reviews, v. 37, n. 7, p. 1308-1319, 2008.

CIRULli, F.; BONSIGNORE, L. T.; VENEROSI, A.; VALANZANO, A.; CHIAROTTI, F.; ALLEVA, E. Long-term effects of acute perinatal asphyxia on rat maternal behavior. Neurobiology and Teratology, v. 25, p. 571-578, 2003.

CLARK, C. R.; GEFFEN, G. M.; GEFFEN, L. B. Catecholamines and attention. I: Animal and clinical studies. Neuroscience Biobehavioral Reviews, v. 11, n. 4, p. 341-52, 1987.

COHEN, M. M. Biochemistry of cerebral anoxia, hypoxia and ischemia. Monographs in Neural Science; p. 1- 49, 1973.

COHEN, D. R.; CURRAN, T. fra-1: a serum-inducible, cellular immediate-early gene that encodes a fos-related antigen. Molecular and Cellular Biology, v. 8, n. 5, p. 2063-2069, 1988.

COHEN, G.; MALCOLM, G.; HENDERSON-SMART, D. Ventilatory response of the newborn infant to mild hypoxia. Pediatric Pulmonology, v. 24, n. 3, p. 163-172, 1997.

CONRAD, L. C.; LEONARD, C. M.; PFAFF, D. W. Connections of the median and dorsal raphe nuclei in the rat: na autoradiographic and degeneration study. Journal of Comparative Neurology, v. 156, n. 2, p. 179-205, 1974.

COQ, J. Q.; STRATA, F.; RUSSIER, M.; SAFADI, F. F.; MAERZENICH, M. M.; BYL, N. N.; BARBE, M. F. Impact of neonatal asphyxia and hind limb immobilization on musculoskeletal tissues 
and S1 map organization: implications for cerebral palsy. Experimental Neurology, v. 210, n. 1, p. 95-108, 2008.

COSTELlO, A. M.; MANANDHAR, D. S. Perinatal asphyxia in less developed countries. Archives of disease in childhood. Fetal and neonatal edition, v. 71, n. 1, p. 1-3, 1994.

CURRAN, T.; MACCONNELL, W. P.; VAN STRAATEN F.; VERMA, I. M. Structure of the FBJ murine osteosarcoma virus genome: molecular cloning of its associated helper virus and the cellular homolog of the v-fos gene from mouse and human cells. Molecular and Cellular Biology, v. 3, n. 5, p. 914-921, 1983.

CURRAN, T.; MILLER, A. D.; ZOKAS, L.; VERMA, I. L. Viral and cellular fos proteins: a comparative analysis. Cell, v. 36, n. 2. p. 259-268, 1984.

DAVIS, J. N.; CARLSSON, A.; MACMILLAN, V.; SIESJÖ, B. K. Brain tryptophan hydroxylation: dependence on arterial oxygen tension. Science, v. 182, n. 107, p. 72-4, 1973.

DECKER, M. J.; CONRAD, K. P.; STROHL, K. P. Noninvasive oximetry in the rat. Biomedical Instrumentation \& Technology, v. 23, n. 3, p. 222-8, 1989.

DELL'ANNA, M. E.; CALZOLARI, S.; MOLINARI, M.; IUVONE, L.; CALIMICI, R. Neonatal anoxia induces transitory hyperactivity, permanent spatial memory deficits and CA1 cell density reduction in developing rats. Behavioral Brain Research, v. 45, n. 2, p. 125-134, 1991.

DELL'ANNA, M.E.; LUTHMAN, J.; LINDQVIST, E.; OLSON, L. Development of Monoamine Systems After Neonatal Anoxia in Rats. Brain Research Bulletin, v. 32, p. 159-170, 1993.

DELL'ANNA, M.E.; GELOSO, M.C.; DRAISCI, G.; LUTHMAN, J. Transient Changes in Fos and GFAP Innumoreactivity Precede Neuronal Loss in the Rat Hippocampus Following Neonatal Anoxia. Experimental Neurology, v. 131, p. 144-156, 1995a.

DELL'ANNA, E.; CHEN, Y.; LOIDL, F.; ANDERSSON, K.; LUTHMAN, J.; GOINY, M.; RAWAL, R.; LINDGREN, T.; HERRERA-MARSCHITZ, M. Short-Term Effects of Perinatal Asphyxia Studied with Fos-Immunocytochemistry and in Vivo Microdialysis in the Rat. Experimental Neurology, v. 131, p. 279-287, 1995 b.

DELL'ANNA E.; IUVONE L.; CALZOLARI S.; GELOSO, M.C. Effect of acetyl-L-carnitine on hyperactivity and spatial memory deficits of rats exposed to neonatal anoxia. Neuroscience Letters, v. 223, p. 201-205, 1997.

DI PASQUALE, E.; MORIN, D.; MONTREAU, R.;HILLAIRE, G. Serotonergic modulation of the respiratory rhythm generator at birth: an in vitro study in the rat. Neuroscience Letters, v.143, p. 9195, 1992.

DOBBING, J. The development of the blood-brain barrier. Progress in Brain Research, v. 29, p. 417-427, 1968.

DOBBING, J. The effects of early growth retardation on the human brain: the usefulness of animal experiments. Journal of Pathology, v. 101, n. 4, p.13, 1970.

DOI, A.; RAMIREZ, J. M. Neuromodulation and the orchestration of the respiratory Rhytm. Respiratory Physiology\&Neurobiology, in press, 2008.

DRAGUNOW M.; FAULL, R. The use of c-fos as a metabolic marker in neuronal pathway tracing. Journal of Neuroscience Methods, v. 29, p. 261-265, 1989. 
DRAISCI, G.; IADAROLA, M. J. Temporal analysis of increases in c-fos, prepodynorphin and preproenkephalin mRNA in rat spinal cord. Molecular Brain Research, v. 6, p. 31-37, 1989.

EDWARDS, A. D.; YUE, X.; COX, P.; HOPE, P. L.; AZZOPADI, D. V.; SQUIER, M. V.; MEHMET, H. Apoptosis in the brains of infants suffering intrauterine cerebral injury. Pediatric Research, v. 42, n. 5, p. 684-689, 1997.

EDWARDS, E.; PATON, J. F. Glutamate stimulation of raphe pallidus attenuates the cardiopulmonary reflex in anaesthetised rats. Autonomic Neuroscience, v. 82, n. 3, p. 87-96, 2000.

EL-KHODOR, B.; BOKSA, P. Differential vulnerability of male versus female rats to long-term effects of birth insult on brain catecholamine levels. Experimental Neurology, v. 182, p. 208-219, 2003.

ELNAZIR, B.; MARSHALL, J. M.; KUMAR, P. Postnatal development of the pattern of respiratory and cardiovascular response to systemic hypoxia in the piglet: the roles of adenosine. Journal of Physiology, v. 492, p. 573-585, 1996.

ENGIDAWORK, E.; CHEN, Y.; DELL'ANNA, E.; GOINY, M.; LUBEC, G.; UNGERSTEDT, U.; ANDERSSON, K.; HERRERA-MARSCHITZ, M. Effect of perinatal asphyxia on systemic and intracerebral pH and glycolysis metabolism in the rat. Experimental Neurology, v. 145, p. 390-396, 1997.

ERICKSON, J. T.; MILLHORN, D. E. Hypoxia and electrical stimulation of the carotid sinus nerve induce Fos-like immunoreactivity within catecholaminergic and serotoninergic neurons of the rat brainstem. Journal of Comparative Neurology, v. 348, n. 2, p. 161-182, 1994.

ERIKSSON, M.; TASKINEN, M.; LEPPÃ, S. Mitogen activated protein kinase-dependent activation of c-Jun and c-Fos is required for neuronal differentiation but not for growth and stress response in PC12 cells. Journal of Celllular Physiology, v. 210, n. 2, p. 538-548, 2007.

FANDREY, J.; GORR, T. A.; GASSMANN, M. Regulating cellular oxygen sensing by hydroxylation. Cardiovascular Research, v. 71, n. 4, p. 642-651, 2006.

FARAONE, S. V.; BIEDERMAN, J. Neurobiology of attention-deficit hyperactivity disorder. Biological Psychiatry, v. 44, n. 10, p. 951-958, 1998.

FINKEL, M. P.; BISKIS, B. O.; JINKINS, P. B. Virus induction of osteosarcomas in mice. Science, v. 151, n. 711, p. 698-701, 1966.

FINLEY, J.C.; KATZ, D.M. The central organization of carotid body afferent projections to the brainstem of the rat. Brain Research , v.572, p. 108-116, 1992.

FLORES, C.; STEWART, J.; SALMASO, N.; ZHANG, Y.; BOKSA, P. Astrocytic basic fibroblast growth factor expression in dopaminergic regions after perinatal anoxia. Biological Psychiatry, v. 52, n. 4, p. 362-370, 2002.

FOSTER, G. A. Chemical neuroanatomy of the prenatal rat brain. 2. ed. New York : Oxford University Press, 1998. 231 p.

FREUND, R. K.; LUNTZ-LEYBMAN, V.; COLLINS, A. C. Nicotine interferes with GABAmediated inhibitory processes in mouse hippocampus. Brain Research, v. 527, n. 2, p. 286-291, 1990. 
GANONG, W. F. Fisiologia Médica. 19. ed. Rio de Janeiro: McGrall-Hill Interamericana do Brasil, 2006. $639 \mathrm{p}$.

GARGAGLIONI, L. H.; BÍCEGO, K. C.; NUCCI, T. B.; BRANCO, L. G. Serotoninergic receptors in the anteroventral preoptic region modulate the hypoxic ventilatory response. Respiratory Physiology \& Neurobiology, v. 153, n. 1, p. 1-13, 2006.

GENEST, S. E.; BALON, N.; LAFOREST, S.; DROLET, G.; KINKEAD, R. Neonatal maternal separation and enhancement of the hypoxic ventilatory response in rat: the role of GABAergic modulation within the paraventricular nucleus of the hypothalamus. Journal of Physiology, v. 583, p. 299-314, 2007.

GERSHAN, W. M.; FORSTER, H. V.; LOWRY, T. F.; KORDUCKI, M. J.; FORSTER, A. L.; FORSTER, M. A.; OHTAKE, P. J.; AARON, E. A.; GARBER, A. K. Effect of metabolic rate on ventilatory roll-off during hypoxia. Journal of Applied Physiology, v. 76, n. 6, p. 2310-2314, 1994.

GILBY, K. L.; ARMSTRONG, J. N.; CURRIE, R. W.; ROBERTSON, H. A. The effects of hypoxiaischemia on expression of c-Fos, c-Jun and Hsp70 in the young rat hippocampus. Molecular Brain Research, v. 48, p. 87-96, 1997.

GILL, K. M.; BERNSTEIN, I. L.; MIZUMORI, S. J. Immediate early gene activation in hippocampus and dorsal striatum: effects of explicit place and response training. Neurobiology of Learning and Memory, v. 87, n. 4, p. 583-596, 2007.

GLOBUS, M. Y.; BUSTO, R.; DIETRICH, W. D.; MARTINEZ, E.; VALDES, I.; GINSBERG, M. D. Effect of ischemia on the in vivo release of striatal dopamine, glutamate, and gamma-aminobutyric acid studied by intracerebral microdialysis. Journal of Neurochemistry, v. 51, n. 5, p. 1455-1464, 1988.

GLUCKMAN, P. D.; PINAL, C. S.; GUNN A. J. Hypoxic-ischemic brain injury in the newborn: pathophysiology and potential strategies for intervention. Seminars in Neonatology, v. 6, n. 2, p. 109$120,2001$.

GOLOMBEK, D.A.; RALPH, M.R. Let there be light: signal transduction in a mammalian circadian system. Brazilian Journal of Medicine Biology Research, v. 29, p. 131-140, 1996.

GORENBERG, D. M.; PATTILlO, C.; HENDI, P.; RUMNEY, P. J.; GARITE, T. J. Fetal pulse oximetry: correlation between oxygen desaturation, duration, and frequency and neonatal outcomes. American Journal of Obstetrics and Gynecology, v. 189, n. 1, p. 136-138, 2003.

GOULD, E.; WOOLF, N. J.; BUTCHER, L. L. Postnatal development of cholinergic neurons in the rat: I. Forebrain. Brain Research Bulletin, v. 27, n. 6, p. 767-789, 1991.

GOURINE, A. V.; LLAUDET E.; DALE, N.; SPYER, K. M. Release of ATP in the ventral medulla during hypoxia in rats: role in hypoxic ventilatory response. Journal of Neuroscience, v. 25, n. 5, p. 1211-1218, 2005.

GOZAL, D.; HATHOUT, G. M.; KIRLEW, K. A.; TANG, H.; WOO, M. S.; ZHANG, J.; LUFKIN, R. B.; HARPER, R. M. Localization of putative neural respiratory regions in the human by functional magnetic resonance imaging. Journal of Applied Physiology, v. 76, n. 5, p. 2076-2083, 1994.

GOZAL, D.; GOZAL, E.; SIMAKAJORNBOOM, N. Signaling pathways of the acute hypoxic ventilatory response in the nucleus tractus solitarius. Respiratory Physiology, v. 121, p. 209-221, 2000a. 
GOZAL, D.; SIMAKAJORNBOOM, N.; CZAPLA, M.A.; XUE, Y.D.; GOZAL, E.; VLASIC, V.; LASKY, J.A.; LIU, J.Y. Brainstem activation os platelet growth factor-beta receptor modulates the late phase of the hypoxic ventilatory response. Journal of Neurochemistry, v. 74, p. 310-319, 2000b.

GREENBERG, M. E.; ZIFF, E. B. Stimulation of 3 T3 cells induces transcription of the c-fos protooncogene. Nature, v. 311, n. 5985, p. 433-438, 1984.

GREENBERG, M. E.; GREENE, L. A.; ZIFF, E. B. Nerve growth factor and epidermal growth factor induce rapid transient changes in proto-oncogene transcription in PC12 cells. Journal of Biological Chemistry, v. 260, n. 26, p. 14101-14110, 1985.

GUNN, A. J.; BENNET, L. Timing of injury in the fetus and neonate. Current Opinion in Obstetrics and Gynecology, v. 20, n. 2, p. 175-181, 2008.

GUNN, A. J.; DRAGUNOW, M.; FAULL, R. L.; GLUCKMAN, P. D. Effects of hypoxia-ischemia and seizures on neuronal and glial-like c-fos protein levels in the infant rat. Brain Research, v. 531, n. 1-2, p. 105-116, 1990.

HAJI A.; TAKEDA, R.; OKAZAKI, M. Neuropharmacology of control of respiratory rhythm and pattern in mature mammals. Pharmacology\&Therapeutics, v. 86, n. 3, p. 277-304, 2000.

HALL, J. E; GUYTON, A. C. Tratado de Fisiologia Médica. 10. ed. Rio de Janeiro: Guanabara Koogan, 2002.

HALLIDAY, G. BAKER, K., HARPER, C. Serotonin and alcohol-related brain damage. Metabolic brain disease, v. 10, n. 1, p. 25-30, 1995.

HAY JR., W. W.; RODDEN, D. J.; COLLINS, S. M.; MELARA, D. L.; HALE, K. A.; FASHAW, L. M. Reliability of conventional and new pulse oximetry in neonatal patients. Journal of Perinatology, v. 22, n. 5, p. 360-366, 2002.

HEDNER, T.; LUNDBORG, P. Serotonin metabolism in neonatal rat brain during asphyxia and recovery. Acta Physiologica Scandinavian, v. 109, p. 163-168, 1980.

HEHRE, D. A.; DEVIA, C. J.; BANCALARI, E.; SUGUIHARA, C. Brainstem amino acid neurotransmitters and ventilatory response to hypoxia in piglets. Pediatric Research, v. 63, n. 1, p. 46-50, 2008.

HERLENIUS, E.; LAGERCRANTZ H. Neurotransmitters and neuromodulators during early human development. Early Human Development, v. 65, p. 21-37, 2001.

HERSCHMAN, H, R, Primary response genes induced by growth factors and tumor promoters. Anual Review of Biochemistry, v. 60, p. 281-319, 1991.

HERSHKOWITZ, M.; GRIMM, V. E.; SPEISER, Z. The effects of postnatal anoxia on behaviour and on the muscarinic and beta-adrenergic receptors in the hippocampus of the developing rat. Brain Research, v. 283, n. 2-3, p. 147-155, 1983.

HIROOKA, Y.; POLSON, J. W.; POTTS, P. D.; DAMPNEY, R. A. Hypoxia-induced Fos expression in neurons projecting to the pressor region in the rostral ventrolateral medulla.Neuroscience, v. $80, \mathrm{n}$. 4, p. 1209-1224, 1997. 
HODGES, M. R.; OPANSKY, C.; QIAN, B.; DAVIS, S.; BONIS, J.; BASTASIC, J.; LEEKLEY, T. PAN, L. G.; FORSTER, H. V. Transient attenuation of CO2 sensitivity after neurotoxic lesions in the medullary raphe area of awake goats. Journal of Applied Physiology, v. 97, n. 6, p. 2236-2247, 2004.

HOFFMAN, G. E.; LYO, D. Anatomical markers of activity in neuroendocrine systems: are we all 'fos-ed out'? Journal of Neuroendocrinology, v. 14, n. 4, p. 259-268, 2002.

HOSOGAI, M.; MATSUO, S.; SIBAHARA, T.; KAWAI, Y. Projection of respiratory neurons in rat medullary raphé nuclei to the phrenic nucleus. Respiratory Physiology, v. 112, n. 1, p. 37-50, 1998.

HURLEY, K. M.; HERBERT, H.; MOGA, M. M.; SAPER, C. B. Efferent projections of the infralimbic cortex of the rat. Journal of Comparative Neurology, v. 308, n. 2, p. 249-276, 1991.

IUVONE, L.; GELOSO, M. C.; DELL'ANNA, E. Changes in open field behavior, spatial memory, and hippocampal parvalbumin immunoreactivity following enrichment in rats exposed to neonatal anoxia. Experimental Neurology, v. 139, n. 1, p. 25-33, 1996.

JOHNSTON, M.V.; NAKAJIMA, W.; HAGBERG, H. Mechanisms of Hypoxic Neurodegeneration in the Developing Brain. The Neuroscientist, v. 8, p. 212-220, 2002.

JUÁREZ, I.; SILVA-GÓMEZ, A. B.; PERALTA, F.; FLORES, G. Anoxia at birth induced hyperresponsiveness to amphetamine and stress in postpubertal rats. Brain Research, v. 992, n. 2, p. 281-287, 2003.

KALIA, M.; RICHTER, D. Rapidly adapting pulmonary receptor afferents: I. Arborization in the nucleus of the tractus solitarius. Journal of Comparative Neurology, v. 274, n. 4, p. 560-573, 1988.

KAUR, C.; YOU, Y.; SINGH, J.; PENG, C. M.; LING, E. A. Expression of Fos immunoreactivity in some catecholaminergic brainstem neurons in rats following high-altitude exposure. Journal of Neuroscience Research, v. 63, n. 1, p. 54-63, 2001.

LALLEY, P.M.; BISCHOFF, A.M.; RICHTER, D.W. Serotonin 1- $\alpha$ receptor activation supresses respiratory apneusis in the cat. Neuroscience Letters, v. 172, p. 59-62, 1994.

LANDSCHULTZ, W. H.; JOHNSON, P. F.; MCKNIGHT, S. L. The leucine zipper: a hypothetical structure common to a new class of DNA binding proteins. Science, v. 240, n. 4860, p. 1759-1764, 1988.

LARSEN, P. J.; MELLER, M.; MIKKELSEN, J. D. Efferent projections from the periventricular and medial parvicellular subnuclei of the hypothalamic paraventricular nucleus to circumventricular organs of the rat: a Phaseolus vulgaris-leucoagglutinin (PHA-L) tracing study. Journal of Comparative Neurology, v. 306, n. 3, p. 462-479, 1991.

LAUDER, J. M.; MOISEIWITSCH, J.; LIU, J.; WILKIE, M. B. Serotonin in development and pathophysiology. In: LOU, H. C.; GREISEN G.; FALCK-LARSEN, J. (Ed.). Brain Lesions in the Newborn. Munksgaard: Alfred Benzon Symposium, 1994. v. 37, p. 60-72.

LAVIOLA, G.; ADRIANI, W.; REA, M.; ALOE, L.; ALLEVA, E. Social withdrawal, neophobia, and stereotyped behavior in developing rats exposed to neonatal asphyxia. Psychopharmacology, v. 175, n. 2, p. 196-205, 2004.

LEE, J.; MEHTA, K.; BLICK, M. B.; GUTTERMAN, J. U.; LOPEZ-BERESTEIN, G. Expression of c-fos, c-myb, and c-myc in human monocytes: correlation with monocytic differentiation. Blood, v. 69, n. 5, p. 1542-1545, 1987. 
LEUTGEB, S.; LEUTGEB, J. K.; BAMES, C. A.; MOSER, E. I.; MCNAUGHTON, B. L.; MOSER, M. B. Independent codes for spatial and episodic memory in hippocampal neuronal ensembles. Science, v. 309, n. 5734, p. 619-623, 2005.

LEVINE, S. Anoxic-ischemic encephalopathy in rats. American Journal of Pathology, v. 36, p. 137, 1960.

LEVITZKY, M. G. Fisiologia Pulmonar. 6. ed. São Paulo: Manole, 2004. 277 p.

LI, Y. W.; DAMPNEY, R. A. Expression of Fos-like protein in brain following sustained hypertension and hypotension in conscious rabbits. Neuroscience,v. 61, n. 3, p. 613-634, 1994.

LING, E. A.; WONG, W. C. Ultrastructure of the area postrema of the monkey, Macaca fascicularis.Histology and Histopathology, v. 2, n. 1, p. 39-48, 1987.

LIU, J.; WU, L. L.; LI, L.; ZHANG, L.; SONG, Z. E. Growth-promoting effect of platelet-derived growth factor on rat cardiac myocytes. Regulatory Peptides, v. 127, n. 1-3, p. 11-18, 2005.

LIU, Q.; LOWRY, T. F.; WONG-RILEY, M. T. Postnatal changes in ventilation during normoxia and acute hypoxia in the rat: implication for a sensitive period. Journal of Physiology, v. 577, p. 957-970, 2006.

LOIDL, C.F.; GAVILANES, A.W.D.; VAN DIJK, E.H.J.; VREULS, W.; BLOKLAND, A.; VLES, J.S.H.; STEINBUSCH, H.W.M.; BLANCO, C.E. Effects of hypothermia and gender on survival and behavior after perinatal asphyxia in rats. Physiology \& Behavior, v. 68, p. 263-269, 2000.

MACHADO, A. B. M. Neuroanatomia Funcional. 2. ed. São Paulo: Atheneu, 2004. 363 p.

MAJEED, R.; MEMON, Y.; MAJEED, F.; SHAIKH, N. P.; RAJAR, U. D. Risk factors of birth asphyxia. Journal of Ayub Medical College, Abbottabad, v. 19, n. 3, p. 67-71, 2007.

MANHÃES DE CASTRO, R.; BARRETO MEDEIROS, J. M.; MENDES DA SILVA, C.; FERREIRA, L. M.; GUEDES, R. C.; CABRAL FILHO, J. E.; COSTA, J. A. Reduction of intraspecific agression in adult rats by neonatal treatment with a selective serotonin reuptake inhibitor. Brazilian Journal of Medical and Biological Research, v. 34, n. 1, p. 121-124, 2001.

MAXOVÁ, H.; VÍZEK, M. Biphasic ventilatory response to hypoxia in unanesthetized rats. Physiological Resesarch, v. 50, n. 1, p. 91-96, 2001.

MCGUIRE, M.; ZHANG, Y.; WHITE, D. P.; LING, L. Chronic intermittent hypoxia enhances ventilatory long-term facilitation in awake rats. Journal of Applied Physiology, v. 95, n. 4, p. 1499$1508,2003$.

McNAMARA, M.C.; GINGRAS-LEATHERMAN, J.L.; LAWSON, E.E. Effect of Hypoxia on Brainstem Concentration of Biogenic Amines in Postnatal Rabbits. Developmental Brain Research, v. 25 , p. $253-258,1986$.

MIKATI, M. A.; ZEINIEH, M. P.; KURDI, R. M.; HARB, S. A. EL HOKAYEM, J. A.; SHAMSEDDINE, A.; OBEID, M.; BITAR, F. F.; EL SABBAN, M. Long-term effects of acute and of chronic hypoxia on behavior and on hippocampal histology in the developing brain. Developmental Brain Research, v. 157, n. 1, p. 98-102, 2005. 
MODALEN, A. Q.; QUIDING, H.; FREY, J.; LINDAHL, S. A novel molecule with peripheral opioid properties: the effects on hypercarbic and hypoxic ventilation at steady-state compared with morphine and placebo. Anesthesia \& Analgesia, v. 102, n. 1, p. 104-109, 2006.

MOORE, R. Y.; ZIEGLER, B.; BAYER, S. A. Monoamine neuron innervation of the hippocampal formation: alteration by neonatal irradiation. Experimental Neurology, v. 60, b. 2, p. 318-326, 1978.

MORGAN, J. I.; CURRAN, T. Stimulus-transcription coupling in neurons: role of cellular immediateearly genes. Trends in Neuroscience, v. 12, n. 11, p. 459-462, 1989.

MORGAN, J. I.; CURRAN, T. Stimulus-transcription coupling in the nervous system: involvement of the inducible proto-oncogenes fos and jun. Annual Reviews - Neuroscience, v. 14, p. 421-451, 1991.

MORGANE, P. J.; AUSTIN-LAFRANCE, R.; BRONZINO, J.; TONKISS, J.; DÍAZ-CINTRA, S.; CINTRA, L.; KEMPER, T.; GALLER, J. R. Prenatal malnutrition and development of the brain. Neuroscience Biobehavioral Reviews, v. 17, n. 1, p. 91-128, 1993.

MORRIS, R. G.; MOSER, E. I.; RIEDEL, G.; MARTIN, S. J.; SANDIN, J.; DAY, M.; O'CARROL, C. Elements of a neurobiological theory of the hippocampus: the role of activity-dependent synaptic plasticity in memory. Philosophical Transactions of the Royal Society of London. Series B. Biological Sciences, v. 358, n. 1432, p. 773-786, 2003.

MULKEY, D. K.; STORNETTA, R. L.; WESTON, M. C.; SIMMONS, J. R.; PARKER, A.; BAYLISS, D. A.; GUYENET, P. G. Respiratory control by ventral surface chemoreceptor neurons in rats. Nature Neuroscience, v. 7, n. 12, p. 1360-1369, 2004.

MÜLLER, R.; VERMA, I. M.; ADAMSON, E. D. Expression of c-onc genes: c-fos transcripts accumulate to high levels during development of mouse placenta, yolk sac and amnion. EMBO Journal, v.2, n. 5, p. 679-684, 1983.

MÜLLER, R.; BRAVO, R.; BURCKHARDT, J.; CURRAN, T. Induction of c-fos gene and protein by growth factors precedes activation of c-myc. Nature, v. 312, n. 5996, p. 716-720, 1984.

NAKABEPPU, Y.; NATHANS, D. The basic region of Fos mediates specific DNA binding. EMBO Journal, v. 8, n. 12, p. 3833-3841, 1989.

NAKAJIMA, W.; ISHIDA, A.; TAKADA, G. Effect of anoxia on striatal monoamine metabolism in immature rat brain compared with that of hypoxia: an in vivo microdialysis study. Brain Research, v. 740, p. 316-322, 1996.

NAKAJIMA, W.; ISHIDA, A.; TAKADA, G. Anoxic and hypoxic immature rat model for measurement of monoamine using in vivo microdialysis. Brain Research Protocols, v. 3, p. 252-256, 1999.

NAKAJIMA, W.; ISHIDA, A.; LANGE, M. S.; GABRIELSON, K. L.; WILSON, M.A .; MARTIN, L. J.; BLUE, M. E.; JOHNSTON, M. V. Apoptosis has a prolonged role in the neurodegeneration after hypoxic ischemia in the newborn rat. Journal of Neuroscience, v. 21, n. 21, p. 7994-8004, 2000.

NAKAZAWA, K.; MCHUGH, T. J.; WILSON, M. A.; TONEGAWA, S. NMDA receptors, place cells and hippocampal spatial memory. Nature Reviews Neuroscience, v. 5, n. 5, p. 361-372, 2004.

NAQUI, S. Z.; HARRIS, B. S.; THOMAIDOU, D.; PARNAVELAS, J. G. The noradrenergic system influences the fate of Cajal-Retzius cells in the developing cerebral cortex. Developmental Brain Research, v. 113, n. 1-2, p. 75-82, 1999. 
NATTIE, E. Multiple sites for central chemoreception: their roles in response sensitivity and in sleep and wakefulness. Respiratory Physiology, v. 122, n. 2-3, p. 223-235, 2001.

NATTIE, E.; PRABHAKAR, N. R. Peripheral and central chemosensitivity: multiple mechanisms, multiple sites? A workshop summary. Advances in Experimental Medicine and Biology, v. 499, p. 73-80, 2001.

NESS, J. M.; HARVEY, C. R.; WASHINGTON, J. D.; ROTH, K.A .; CARROLL, S. L.; ZHANG, J. Differential activation of c-fos and caspase-3 in hippocampal neuron subpopulations following neonatal hypoxia-ischemia. Journal of Neuroscience Research, v. 86, v. 5, p. 1115-1124, 2008.

NEWTON, B. W.; MALEY, B.; SASEK, C.; TRAURIG, H. Distribution of FMRF-NH2-like immunoreactivity in rat and cat area postrema. Brain Reasearch Bulletin, v. 13, n. 3, p. 391-399, 1984.

NISHINA, H.; SATO, H.; SUZUKI, T.; SATO, M.; IBA, H. Isolation and characterization of fra-2, an additional member of the fos gene family. The Proceedings of the National Academy of Sciences, v. 87, n. 9, p. 3619-3623, 1990.

NORTHINGTON, F. J.; FERRIERO, D. M.; GRAHAM, E. M.; TRAYSTMAN, R. J.; MARTIN, L. J. Early Neurodegeneration after Hypoxia-Ischemia in Neonatal Rat Is Necrosis while Delayed Neuronal Death Is Apoptosis. Neurobiology Disorders, v. 8, n. 2, p. 207-219, 2001.

NORTON, J.; JACKSON, P. G.; TAYLOR, P. M. Measurement of arterial oxygen-haemoglobin saturation in newborn lambs by pulse oximetry. The Veterinary Record, v. 142, n. 5, p. 107-109, 1998.

NYAKAS, C.; BUWALDA, B.; LUITEN, P.G.M. Hypoxia and Brain Development. Progress in Neurobiology, v. 49, p. 1-51, 1996.

OHTAKE, P.J.; TORRES, J.E.; GOZAL, Y.M.; GRAFF, G.R., GOZAL D. NMDA receptors mediate peripheral chemoreceptor afferent input in the conscious rat. Journal of Applied Physiology, v. 84, p. 853-861, 1998.

OHTAKE, P. J.; SIMAKAJORNBOON, N.; FEHNIGER, M. D.; XUE, Y. D.; GOZAL, D. N-Methyl$\mathrm{D}$-aspartate receptor expression in the nucleus tractus solitarii and maturation of hypoxic ventilatory response in the rat. American Journal of Respiratpry and Critical Care Medicine, v. 162, n. 3, p. $1140-1147,2000$.

OLIVEIRA-ALONSO G. S.; SILVEIRA V. C.. Lesões encefálicas infantis adquiridas. In: FERNANDES, A. C.; RAMOS, A. C. R.; CASALIS, M. E. P.; HEBERT, S. K. (Ed). AACD Medicina e Reabilitação: princípios e prática. São Paulo: Artes Médicas, 2007. p. 161-172.

OORSCHOT, D.E.; BLACK, M.J.; RANGI, F.; SCARR, E. Is Fos Protein Expressed by Dying Striatal Neurons after Immature Hypoxic-Ischemic Brain Injury? Experimental Neurology, v. 161, p. 227-233, 2000.

PAXINOS, G.; ASHWELL, K.W.S.; TÖRK, I. Atlas of the Developing Rat Nervous System. 2. ed. San Diego: Academic Press, 1994.

PEEVER, J. H.; NECAKOV, A.; DUFFIN, J. Nucleus raphé obscurus modulates hypoglossal output of neonatal rat in vitro transverse brain stem slices. Journal of Applied Physiology, v. 90, n. 1, p. 269-279, 2001. 
PENDLETON, R. G.; RASHEED, A.; ROYCHOWDHURY, R. HILLMAN, R. A new role for catecholamines: ontogenesis. Trend in Pharmacological Sciences, v. 19, n. 7, p. 248-251, 1998.

PETROVA, A.; MEHTA, R. Near-infrared spectroscopy in the detection of regional tissue oxygenation during hypoxic events in preterm infants undergoing critical care. Pediatric Critical Care Medicine, v. 7, n. 5, p. 449-454, 2006.

POTHUIZEN, H. H.; AGGLETON, J. P.; VANN, S. D. Do rats with retrosplenial cortex lesions lack direction? European Journal of Neuroscience, v. 28, n. 12, p. 2486-2498, 2008.

POWELL, F.L.; MILSOM, W.K.; MITCHELL, G.S. Time domains of the hypoxic ventilatory response. Respiratory Physiology, v. 112, p. 123-134, 1998.

PUTNAM, R. W.; FILOSA, J. A.; RITUCCI, N. A. Cellular mechanisms involved in CO(2) and acid signaling in chemosensitive neurons. American Journal of Physiology and Cellular Physiology, v. 287, n. 6, p. 1493-1526, 2004.

RAJAKUMAR, N.; HRYCYSHYN, A. W.; FLUMERFELT, B. A. Afferent organization of the lateral reticular nucleus in the rat: an anterograde tracing study. Anatomy and Embriology, v. 185, n. 1, p. 25-37, 1992.

RASKIN, L. A.; SHAYWITZ, S. E.; SHAYWITZ, B. A.; ANDERSON, G. M.; COHEN, D. J. Neurochemical correlates of attention deficit disorder. Pediatric Clinics of North America, v.31, p. 387-396, 1984.

REEVES, S. R.; GOZAL, D. Protein kinase C activity in the nucleus tractus solitarii is critically involved in the acute hypoxic ventilatory response, but is not required for intermittent hypoxiainduced phrenic long-term facilitation in adult rats. Experimental Physiology, v. 92, n. 6, p. 10571066, 2007.

RICE, J. E. $3^{\text {RD }}$; VANNUCCI, R. C.; BRIERLEY, J. B. The influence of immaturity on hypoxicischemic brain damage in the rat. Annals of Neurology, v. 9, n. 2, p. 321-329, 2004.

RICHERSON, G. B. Serotonergic neurons as carbon dioxide sensors that maintain $\mathrm{pH}$ homeostasis. Nature Reviews Neuroscience, v. 5, n. 6, p. 449-461, 2004.

RICHERSON, G. B.; WANG, W.; TIWARI, J.; BRADLEY, S. R. Chemosensitivity of serotonergic neurons in the rostral ventral medulla. Respiratory Physiology, v. 129, n. 1-2, p. 175-189, 2001.

ROGALSKA, J.; CAPUTA, M.; WENTOWSKA, K.; NOWAKOWSKA, A. Stress-induced behaviour in juvenile rats: effect of neonatal asphyxia, body temperature and chelation of iron. Behavioural Brain Research, v. 154, p. 321-329, 2004.

ROGALSKA, J.; CAPUTA, M.; WENTOWSKA, K.; NOWAKOWSKA, A. Stress-induced behaviour in adult and old rats: effects of neonatal asphyxia, body temperature and chelation of iron. Journal of Physiology and Pharmacology, v. 57, n. 8, p. 17-34, 2006.

RUIGROK, T. J.; CELLA, F.; VOOGD, J. Connections of the lateral reticular nucleus to the lateral vestibular nucleus in the rat. A anterograde tracing study with Phaseolus vulgaris leucoagglutinin. European Journal of Neuroscience, v. 7, n. 6, p. 1410-1413, 1995.

SAPER, C.B. In: PAXINOS, G. The rat nervous system. 2. ed. San Diego: Academic Press, 1995. p. 107-128. 
SANDAGER-NIELSEN, K.; ANDERSEN, M. B.; SAGER, T. N.; WERGE, T.; SCHEEL-KRÜGER, J. Effects of postnatal anoxia on striatal dopamine metabolism and prepulse inhibition in rats. Pharmacology, Biochemistry and Behavior, v. 77, p. 767-774, 2004.

SCHMIDT-KASTNER, R.; FREUND, T. F. Selective vulnerability of the hippocampus in brain ischemia. Neuroscience, v. 40, n. 3, p. 599-636, 1991.

SCHULZ, J. B.; WELLER, M.; MOSKOWITZ, M. A. Caspases as treatment targets in stroke and neurodegenerative diseases. Annals of Neurology, v. 45, n. 4, p. 421-429, 1999.

SEMENZA, G. L. Surviving ischemia: adaptive responses mediated by hypoxia-inducible factor 1 . Journal of Clinical Investigation, v. 106, n. 7, p. 809-812, 2000.

SHAPIRO, R. E.; MISELIS, R. R. The central neural connections of the area postrema of the rat. Journal of Comparative Neurology, v. 234, n. 5, p. 344-364, 1985.

SHAULIAN, E.; KARIN, M. AP-1 as a regulator of cell life and death. Nature Cell Biology, v. 4, n. 5, p. 131-136, 2002.

SHENG, M.; GREENBERG, M. E. The regulation and fucntion of c-fod and other immediate early genes in nervous system. Neuron, v. 4, n. 4, p. 477-485, 1990.

SHIMADA, Y.; YOSHIYA, I.; OKA, N.; HAMAGURI, K. Effects of multiple scattering and peripheral circulation on arterial oxygen saturation measured with a pulse-type oximeter. Medical \& Biological Engineering \& Computing, v. 22, n. 5, p. 475-478, 1984.

SHIPLEY, M. T.; ADAMEK, G. D. The connections of the mouse olfactory bulb: a study using orthograde and retrograde transport of wheat germ agglutinin conjugated to horseradish peroxidase. Brain Research Bulletin, v. 12, n. 6, p. 669-688, 1984.

SILVERTHORN, D. U. Fisiologia Respiratória. In: SILVERTHORN, D. U. Fisiologia Humana: uma abordagem integrada. 2. ed. São Paulo: Manole, 2003, p. 497-535.

SIMAKAJORNBOON, N.; KUPTANON, T. Maturational changes in neuromodulation of central pathways underlying hypoxic ventilatory response. Respiratory Physiology \& Neurobiology, v. 30, p. 1-14, 2005.

SMITH, D. W.; BULLER, K. M.; DAY, T. A. Role of ventrolateral medulla catecholamine cells in hypothalamic neuroendocrine cell responses to systemic hypoxia. Journal of Neuroscience, v. 15, n. 12, p. 7979-7988, 1995.

SPEISER, Z.; KATZIR, O.; REHAVI, M.; ZABARSKI, T. COHEN, S. Sparing by rasagiline (TVP1012) of cholinergic functions and behavior in the postnatal anoxia rat. Pharmacology Biochemistry and Behavior, v. 60, n. 2, p. 387-393, 1998.

SPENCER, D. J. Jr.; PONTECORVO, M. J.; HEISE, G. A. Central cholinergic involvement in working memory: effects of scopolamine on continuous nonmatching and discrimination performance in the rat. Behavioral Neuroscience, v. 99, n. 6, p. 1049-1065, 1985. 
STRATA, F.; COQ, J. O.; BYL, N.; MERZENICH, M. M. Effects of sensorimotor restriction and anoxia on gait and motor cortex organization: implications for a rodent model of cerebral palsy. Neuroscience, v. 129, n. 1, p. 141-156, 2004.

SUBRAMANIAN, H. H.; BALNAVE, R. J.; HOLSTEGE, G. The midbrain periaqueductal gray control of respiration. Journal of Neuroscience, v. 28, n. 47, p. 12274-12283, 2008.

SUGUIHARA, C.; LESSA, A. C. Strategies to minimize lung injury in extremely low birth weight infants. Jornal de Pediatria, Rio de Janeiro, v. 81, p. 69-78, 2005. Suppl. 1.

SUNDSTRÖM, E.; KÖLARE, S.; SOUVERBIE, F.; SAMUELSSON, E. B.; PSCHERA, H.; LUNELL, N. O.; SEIGER, A. Neurochemical differentiation of human bulbospinal monoaminergic neurons during the first trimester. Developmental Brain Research, v. 75, n. 1, p. 1-12, 1993.

SWEDLOW, D. B. Review of evidence for a fetal SpO2 critical threshold of 30\%. Nellcor Puritan Bennett Perinatal Note, v. 2, p. 1-9, 1997.

TANG, A. C.; NAKAZAWA, M. Neonatal novelty exposure ameliorates anoxia-induced hyperactivity in the open field. Behavioural Brain Research, v. 163, n. 1, p. 1-9, 2005.

TEATHER, L. A.; PACKARD, M. G.; SMITH, D. E.; ELLIS-BEHNKE, R. G.; BAZAN, N. G. Differential induction of c-Jun and Fos-like proteins in rat hippocampus and dorsal striatum after training in two water maze tasks. Neurobiology of Learning and Memory, v. 84, n. 2, p. 75-84, 2005 .

TEICHTAHL, H.; WANG, D.; CUNNINGTON, D.; QUINNELL, T.; TRAN, H.; KRONBORG, I.; DRUMMER, O. H. Ventilatory responses to hypoxia and hypercapnia in stable methadone maintenance treatment patients. Chest, v. 128, n. 3, p. 1339-1347, 2005.

TEN, V. S.; BRADLEY-MOORE, M.; GINGRICH, J. A.; STARK, , J,; PINSKY, D. J. Brain injury and neurofunctional deficit in neonatal mice with hypoxic-ischemic encephalopathy. Behavioral Brain Research, v. 145, n. 1-2, p. 209-219, 2003.

TREMPER, K. K.; BARKER, S. J. Pulse oximetry. Anesthesiology, v. 70, n. 1, p. 98-108, 1989.

TREPEL, M. Neuroanatomia: estrutura e função. 2. ed. Rio de Janeiro: Revinter, 2005, 359p.

TRYBA, A. K.; PEIIA, F.; RAMIREZ, J. M. Gasping activity in vitro: a rhythm dependent on 5HT2A receptors.Journal of Neuroscience, v. 26, n. 10, p. 2623-2634, 2006.

VAN BEVEREN, C.; VAN STRAATEN, F.; CURRAN, T.; MÜLLER, R.; VERMA, I. M. Analysis of FBJ-MuSV provirus and c-fos (mouse) gene reveals that viral and cellular fos gene products have different carboxy termini. Cell, v. 32, n. 4, p. 1241-1255, 1983.

VANNUCCI, R.C. Hypoxia-ischemia: Clinical aspects. In: FANAROFF, A. A.; MARTIN R. J. (Ed.) Neonatal perinatal medicine. 4. ed. Philadelphia: Mosby-Yearbook, 1997. p. 877-891.

VANNUCCI, R.C.; CONNOR, J.R.; MAUGER, D.T.; PALMER, C.; SMITH, M.B.; TOWFIGHI, J.; VANNUCCI, S.J. Journal of Neuroscience Research, v. 55, p. 155-163, 1999.

VANNUCCI, R.C. Hypoxic-ischemic Encephalopathy. American Journal of Perinatology, v. 17, p. 113-120, 2000. 
VENEROSI, A.; VALANZANO, A.; CIRULLI F.; ALLEVA, E.; CALAMANDREI, G. Acute global anoxia during $\mathrm{C}$-section birth affects dopamine-mediated behavioural responses and reactivity to stress. Behavioural Brain Research, v. 154, p. 155-164, 2004.

VEXLER, Z.S.; FERRIERO, D.M. Molecular and biochemical mechanisms of perinatal brain injury. Seminars in Neonatology, v.6, p. 99-108, 2001.

VIZEK, M.; PICKET, C.K.; WEIL, J.V. Biphasic ventilatory response of adult cats to sustained hypoxia has central origin. Jornal of Applied Physiology, v. 63, p. 1658-1664, 1987.

VLASIC, V.; SIMAKAJORNBOOM, N.; GOZAL E.; GOZAL, D. PDGF-beta receptor expression in the dorsocaudal brainstem parallels hypoxic ventilatory depression in the developing rat. Pediatric Research, v. 50, n. 2, p. 236-241, 2001.

VOLPE, J.J. Perinatal hypoxic-ischemic brain injury: overview. In: FUKUYAMA, Y.; SUZUKI, Y.; KAMOSHITA, S; CASAER, P. (Ed.). Fetal and Perinatal Neurology. Tokyo: Joint Convention of the 5th International Child Neurology and the 3rd Asian and Oceanian Congress of Child Neurology, 1992. p. 232-252.

VOSS, M. D.; DE CASTRO, D.; LIPSKI, J.; PILOWSKY, P. M.; JIANG, C. Serotonin immunoreactive boutons form close appositions with respiratory neurons of the dorsal respiratory group in the cat. Journal of Comparative Neurology, v. 295, n. 2, p. 208-218, 1990.

WAINWRIGHT, M.S.; CRAFT, J.M.; GRIFFIN, S.T.; MARKS, A.; PINEDA, J.; PADGETT, K.R.; ELDIK, V. Increased Susceptibility of S100B Transgenic Mice to Perinatal Hypoxia-Ischemia. Annals of Neurology, v. 56, p. 61-67, 2004.

WEINBWEGER, C.; THOMPSON, C. C.; ONG, E. S.; LEBO, R.; GRUOL, D. J.; EVANS, R. M. The c-erb-A gene encodes a thyroid hormone receptor. Nature, v. 324, n. 6098, p. 641-646, 1986.

WENK, G.; HUGHEY, D.; BOUNDY, V.; KIM, A.; WALKER, L.; OLTON, D. Neurotransmitters and memory: role of cholinergic, serotonergic, and noradrenergic systems. Behavioral Neurscience, $v$. 101, n. 3, p. 325-332, 1987.

WHITNEY, G. M.; OHTAKE, P. J.; SIMAKAJORNBOOM, N.; XUE, Y. D.; GOZAL, D. AMPA glutamate receptors and respiratory control in the developing rat: anatomic and pharmacological aspects. American Journal of Physiology - Regulatory, Integrative and Comparative Pysiology, v. 278, n. 2 , p. $520-528,2000$.

WILSON-COSTELLO, D.; FRIEDMAN, H.; MINICH, N. Improved survival rates with increased neurodevelopmental disability for extremely low birth weight infants in the 1990s, Pediatrics, v. 115, p. 997-1003, 2005.

WINICK, M.; NOBLE, A Cellular response in rats during malnutrition at various ages. Journal of Nutrition, v. 89, n. 3, p. 300-306, 1966.

WONG-RILEY, M. T.; LIU, Q. Neurochemical development of brain stem nuclei involved in the control of respiration. Respiratory Physiology and Neurobiology, v. 149, n. 1-3, p. 83-98, 2005.

XIA, Y.; HADDAD, G.G. Ontogeny and distribution of opioid receptors in the rat brainstem. Brain Research, v. 549, p. 181-193, 1991

YAMAMOTO, H.; KATO, T. The effect of neonatal anoxia on brain cholecystokinin-8-like immunoreactivity and monoamine levels of mature rats. Brain Research, v. 391, n. 2, 285-288, 1986. 
ZERIAL, M.; TOSCHI, L.; RYSECK, R. P.; SCHUERMANN, M.; MÜLLER, R.; BRAVO, R. The product of a novel growth factor activated gene, fos B, interacts with JUN proteins enhancing their DNA binding activity. EMBO Journal, v. 8, n. 3, p. 805-813, 1989. 